\title{
The Construction and Interpretation of Combined Cross-Section and Time-Series Inequality Datasets
}

\author{
Joseph F. Francois \\ Tinbergen Institute (Erasmus University Rotterdam) and CEPR \\ Hugo Rojas-Romagosa \\ Timbergen Institute (Erasmus University Rotterdam)
}

\begin{abstract}
The inequality dataset compiled in the 1990s by the World Bank and extended by the UN has been both widely used and strongly criticized. The criticisms raise questions about conclusions drawn from secondary inequality datasets in general. We develop techniques to deal with national and international comparability problems intrinsic to such datasets. The result is a new dataset of consistent inequality series, allowing us to explore problems of measurement error. In addition, the new data allow us to perform parametric non-linear estimation of Lorenz curves from grouped data. This in turn allows us to estimate the entire income distribution, computing alternative inequality indexes and poverty estimates. Finally, we have used our broadly comparable dataset to examine international patterns of inequality and poverty.

Keywords: Income distribution datasets, inequality trends, Lorenz curve estimation, poverty estimation

JEL codes: D31, C80, O15
\end{abstract}

\footnotetext{
World Bank Policy Research Working Paper 3748, October 2005

The Policy Research Working Paper Series disseminates the findings of work in progress to encourage the exchange of ideas about development issues. An objective of the series is to get the findings out quickly, even if the presentations are less than fully polished. The papers carry the names of the authors and should be cited accordingly. The findings, interpretations, and conclusions expressed in this paper are entirely those of the authors. They do not necessarily represent the view of the World Bank, its Executive Directors, or the countries they represent. Policy Research Working Papers are available online at http:/ / econ.worldbank.org.
}

We acknowledge support from the EU research and training network (RTN) "Trade, Industrialization, and Development," as well as research support from DFID and the World Bank.

Address correspondence to: J. Francois, Tinbergen Institute, Erasmus University Rotterdam, Burg Oudlaan 50-H8-18, 3000DR Rotterdam, NETHERLANDS.

Email: francois@few.eur.nl.

Data are available at www.intereconomics.com/francois/data.html. 


\section{Non-technical Summary}

The empirical study of cross-country inequality benefits from, but is also limited by, the heterogeneity and vast amount of available data. The inequality dataset compiled in the 1990s by the World Bank and extended by the UN has been both widely used and strongly criticized. The criticisms raise questions about conclusions drawn from secondary inequality datasets in general. We develop techniques to deal with national and international comparability problems intrinsic to such datasets. The result is a new dataset of consistent inequality series, allowing us to explore problems of measurement error. Our approach yields six main inequality series that can readily be used in empirical tests and within these series the implicit measurement error has been reduced.

In addition, the new data allow us to perform parametric non-linear estimation of Lorenz curves from grouped data. This in turn allows us to estimate the entire income distribution, computing alternative inequality indexes and poverty estimates. Working with these data, we introduce improvements to existing methods for estimating Lorenz curves from grouped data. Furthermore, using the resulting estimated Lorenz curves one can estimate Atkinson indexes, which are a complement to the information provided by the Gini coefficient. We find that in roughly a third of the cases both indexes report different inequality trends and thus, the use of both indexes is advisable in order to obtain robust conclusions about income inequality.

Finally, we have used our broadly comparable dataset to examine international patterns of inequality and poverty. A first conclusion is that between-country inequality variation is more significant than within-country. This suggests that country specific characteristics have a bigger role in explaining inequality levels than time trends. However, we also find that within-country inequality is still important and there are significant time trends in our series. Therefore, we reject the "glacial change" hypothesis that inequality does not vary significantly over time. For the specific case of OECD countries, we clearly detect a U-shape pattern that confirms the "U-turn" hypothesis recently flagged by Atkinson. For developing countries the cross-country pattern is less clear, but it suggests a decrease in inequality for most of the analyzed period, with a slight increase in the 1990s. Country-specific time trends are diverse and it is difficult to spot precise trends. The choice of income concept, basic or extended series and the use of pool data may produce different results. Nevertheless, this variety of choice emphasizes the richness of our inequality dataset, which is not limited by a single series and provides wider information from where to draw conclusions. With respect to poverty, we find a decline in the poverty ratios in most of the countries covered by our sample. The only (though admittedly quite significant) exception is the poverty experience in the African continent. 


\section{Overview}

There is a sizeable literature regarding the interaction between income inequality and other economic variables, such as growth, poverty, trade and economic policy. Beginning with Kuznets (1955), the theoretical work has steadily grown, and recently there has been a surge in the topic, reflected in a new wave of publications (Atkinson, 1997). Yet, the study of income inequality has been seriously limited by data constraints. The introduction of a cross-country inequality dataset by the World Bank (Deininger and Squire, 1996) has complemented the recent literature and has itself launched a series of influential econometric studies.

While at the core of most recent work in the area, the structure of the inequality dataset compiled by Deininger and Squire, henceforth DS, recently has been criticized by Atkinson and Brandolini (2001), henceforth AB. These criticisms also extend implicitly to the recent extension of the DS data in the World Income Inequality Dataset (WIID). AB forcefully argue for the need to assess the mechanical use of such "secondary" datasets and to deal more systematically with the measurement problems involved. In this paper we do this, focusing on the empirical and theoretical difficulties related to income inequality measurement, analyzing the characteristics of secondary datasets, and developing a methodological approach for reducing the measurement error problems common to inequality information.

Substantial difficulties arise in the empirical measurement of inequality. The most basic is the lack of an institution and agreed procedures that can assure data quality and consistency. In other words, there is no equivalent to the United Nations System of National Accounts, which provides macroeconomic statistics that are constructed by national agencies and are reasonably consistent over time and countries. In the absence of such an institution, some organizations have constructed "secondary" datasets, of which the best known are DS, the World Income Inequality Database (UNU/WIDER-UNDP, 2000) and the Luxembourg Income Study (LIS). These datasets compile available national inequality statistics and perform quality assessments of all the data observations. This has been an important first step towards the creation of internationally comparable inequality time series. The Deininger and Squire dataset combines a large number of inequality observations

for the entire world, with each observation classified following three quality criteria. More recently, the World Income Inequality Database (WIID) has extended and updated the DS dataset, using similar quality criteria. (Throughout this paper, we use the larger compilation of data provided by the WIID as our main inequality data source.) 
Beyond quality criteria issues, there are additional problems that increase the measurement error present in national series and in international inequality comparisons. In particular, national inequality statistics generally include observations that differ on concepts measured (i.e. expenditure, gross and net income), reference units (e.g. household, person, family) and/or sources. Subsequently we refer to these three distinctive characteristics as the inequality data definitions and we consider an inequality series to be consistent when these definitions are comparable for all observations. Although some countries have relatively extensive and consistent time series, the general rule is that inequality observations are sparse and differ on definitions over time. Hence, to create relatively extensive inequality time series that can be used in econometric studies, it is often necessary to assume the comparability of some of the definitions to handle the problem of sparsity. Deininger and Squire have assumed that all definitions are broadly comparable and used their "high quality" observations to construct the most consistent inequality time series for each country. However, they caution about the potential problems of this comparability assumption and as an alternative they advise the use of dummy variables to adjust and account for different definitions. Using this approach, they generated a single inequality series for a wide number of countries, which has since feature prominently in subsequent empirical research. While convenient, these simplifying assumptions (i.e. the complete comparability of definitions and sources), introduce false patterns and noise into the data. Furthermore, as $\mathrm{AB}$ have stressed, the use of dummy variables is not an adequate solution to this problem.

In this paper, we build on previous efforts to overcome known limitations with secondary inequality datasets. In particular, we assemble a combined inequality dataset based on a consistent grouping methodology of heterogeneous observations from existing secondary datasets. This yields a new cross-section and time-series dataset that we use to examine comparability problems, and to then revisit recent estimates of the relationships between income distribution and other macroeconomic variables. Our approach yields six main inequality series that can readily be used in empirical tests and within these series the implicit measurement error has been reduced. We also explore conceptual issues of measurement. There are important theoretical considerations with regard to inequality measurement. While there are several indicators that measure inequality, there is no consensus in favor of any particular index. ${ }^{1}$ We use non-linear parametric estimation of Lorenz

\footnotetext{
${ }^{1}$ A comprehensive survey of the topic can be found in Cowell (2000).
} 
curves to approximate the entire income distribution, and then use these estimates to calculate the Gini coefficient, four different Atkinson indexes, and poverty rates.

We also use our broadly comparable dataset to examine international patterns of inequality and poverty. A first conclusion is that between-country inequality variation is more significant than within-country. This suggests that country specific characteristics have a bigger role in explaining inequality levels than time trends. However, we also find that within-country inequality is still important and there are significant time trends in our series. Therefore, we reject the "glacial change" hypothesis that inequality does not vary significantly over time. For the specific case of OECD countries, we clearly detect a U-shape pattern that confirms the "U-turn" hypothesis recently flagged by Atkinson (2003). For developing countries the cross-country pattern is less clear, but it suggests a decrease in inequality for most of the analyzed period, with a slight increase in the 1990s. Country-specific time trends are diverse and it is difficult to spot precise trends. The choice of income concept, basic or extended series and the use of pool data may produce different results. Nevertheless, this variety of choice emphasizes the richness of our inequality dataset, which is not limited by a single series and provides wider information from where to draw conclusions. With respect to poverty, we find a decline in the poverty ratios over time in most of the countries covered by our sample. The only (though admittedly quite significant) exception is the poverty experience in the African continent.

The paper is organized as follows. Section 2 explores difficulties involved in dealing with inequality data. In the Section 3 we assess comparability criteria and discuss the resulting assumptions needed in order to consistently group different definitions and sources. In Section 4 we estimate the Lorenz curves and Atkinson indexes from grouped income data, and also poverty ratios. Working with the resulting dataset, in Section 5 we compare it with the DS and WIID series, and also compare the results provided alternatively by the Gini and the Atkinson indexes. In Section 6 we then explore how international and inter-temporal inequality has changed over time within our dataset. We conclude in Section 7.

\section{Problems when dealing with inequality data}

We divide the tasks involved in building a cross-country inequality dataset into two main groups. The first group includes data compilation and quality control. These issues are relatively well 
addressed by existing datasets. The second group includes those issues that are not yet convincingly tackled: the inter-temporal and international comparability and consistency of inequality data.

\subsection{Secondary datasets}

A "secondary" dataset is a summary of national information that is drawn from household income studies and micro-datasets produced by national surveys. The two most used datasets are the Deininger and Squire (DS) and the World Income Inequality Database (WIID). The WIID was constructed itself based on the DS dataset and has expanded this dataset and aggregated new available information. Thus, this is the largest and most exhaustive compilation of inequality data available. It provides up to 5067 data observations, for different definitions, coverage and quality ratings. Therefore, we take it as our starting point and main source of information.

The secondary datasets provide two important advantages. They compile most of the available inequality data into one source, and they check for the quality of each observation. The quality controls used to filter information from the primary to the secondary datasets eliminate unreliable data and inequality observations that are not representative of the whole country. Deininger and Squire (1996) used three quality controls:

"The statistics were selected by requiring that they be from national household surveys for expenditure or income, that they be representative of the national population, and that all sources of income or expenditure be accounted for."

The WIID quality ratings are very similar to those of DS. However, there are some important differences. ${ }^{2}$ In particular, the WIID considers as reliable data some of the observations that did not have a clear reference to the primary source, while DS did not consider these observations in their "high quality" dataset. ${ }^{3}$ The second important difference is the inclusion of observations based on monetary income, which is not used in DS because it does not account for all sources of income. ${ }^{4}$ Finally, missing income concepts are not accepted by WIID and this implies that we do not consider

2 These quality criteria differences introduce some divergences between our dataset and DS, which are not accounted for by the comparability assumptions we use later.

${ }^{3}$ As explained later, the inclusion of these observations significantly increases the number of inequality data points in the 1960s and 1970s. Although the measurement accuracy may be reduced, it provides a valuable extension in the time series (Barro, 2000).

${ }^{4}$ We justify the inclusion of these observations in the following section. Mainly, the data included are from rich or middle-income countries, for which non-monetary income is not expected to be significant. 
some of the DS observations. The reliable data ratings of the WIID are labeled as OKIN and from a total world population of 150 countries, we have OKIN data for 141 countries.

The main difference between DS and WIID, however, is that the last does not identify a single time series for each country. Instead, the researcher has the full available information and has a wide range of series to choose from. The disadvantage is that there is no clear indication on how to use or join inequality observations with different definitions and/or sources.

Finally, it is important to mention that another source of inequality data, which we do not use, is from the micro datasets provided by the Luxembourg Inequality Study (LIS) and the Living Standards Measurement Study of the World Bank. We do not consider their use here because their coverage, in terms of time and countries, is very limited. In addition, they are usually difficult to access and obtaining summary statistics is very time consuming in an already burdensome process. ${ }^{5}$

\subsection{Definition inconsistency}

We follow the WIID and classify each data observation into six characteristics: concept measured, reference unit, area coverage, population coverage, data sources and quality ratings. Technically there are other distinctive characteristics that may significantly alter the inequality values, such as: survey methods, sample characteristics, income issues included (e.g. imputed rents for own-occupied houses, insurance premia, interests and dividends) and the time period considered. ${ }^{6}$ Nevertheless, since our goal is to obtain a reliable cross-country dataset, we do not deal with these measurement issues, which are generally country-specific, and we focus instead on the broad characteristics of the inequality observations. Thus, our resulting dataset diminishes the measurement error embedded in inequality data, but does not entirely eliminate this problem.

From the six main characteristics, we follow DS and select only data that cover the entire population and have national coverage. Moreover, we use the quality criteria provided by the WIID and select only the observations labeled as OKIN. After this first filtering of the information, we remain with three characteristics: concept measured, reference unit and source. Since there are multiple combinations of concepts and reference units, and usually more than one source per country, we have what $\mathrm{AB}$ refer to as a "bewildering variety of estimates". That is, a number of

\footnotetext{
${ }^{5}$ Nonetheless, these data sets may be a preferable source of information for single country inequality analysis or limited cross-country analysis.

${ }^{6}$ Some of these issues can induce substantial measurement errors of their own. For example, imputed rents can represent a significant share of household income in some countries and if it is included in the household survey it can create an important source of distortion in the comparability of different inequality observations. Ravallion and Chen (1997) and Atkinson and Bourguignon (2000) discuss further on these points.
} 
generally discontinuous series, with differences in one or two definitions and usually from different sources. The problem can be better understood by looking at Table 1, which presents data for Chile.

For this particular country we have seven different series, two income concepts (gross income and gross monetary income), two recipients or reference units (person and household) and six sources. However, the number of series and definitions involved can be larger in other countries. In total, there are five different concepts and as many as nine different income recipients. ${ }^{7}$ Additionally each data point provides the Gini coefficient and sometimes distribution shares in quintiles or deciles of population. In Table 1 the observations with distribution shares are indicated by the data in boxes. Moreover, the Gini coefficient can be given by the primary source or directly estimated from the distribution shares when available.

These characteristics of the inequality data leave several questions to be answered. Can we mix different definitions of income concepts and income recipients? Can we mix different sources? If yes, how do we mix them? Which data observation should we choose when there is more than one available for a given year? How many series should we analyze per country? In order to have an inequality dataset that can be readily used for empirical research we must answer these questions, which are relevant if we want to analyze country time series, as well as cross-country analysis. Given that especially in developing countries there are not many inequality observations, we must formulate assumptions regarding the combination of the different definitions in order to obtain at least one series per country.

\subsection{Deininger and Squire approach}

DS assume that all definitions are broadly comparable and instead, focus on the quality of the observations. Thus, they freely mix the different definitions, regardless of income concept or reference unit. However, they acknowledge the potential measurement errors that this approach may cause and recommend the use of dummy variables to deal with the problem.

This strategy allows them to present a single time series for each country, which is very convenient for empirical studies. Moreover, when there is more than one observation per year that satisfies their three quality criteria, they choose the observation that is most consistent with the rest of the series. In other words, they try to maintain the same income concept, recipient unit and

\footnotetext{
7 The concepts are gross income, gross monetary income, net income, net monetary income and expenditure. The most common reference units are person, household, household per capita, household equivalent, family and family equivalent.
} 
source when possible. Their final inclusion criterion is that the observation originates from an official publication. In the last column of Table 1, we present their "high-quality" data observations, which are labeled as DS-accept. For this particular country, they mix household and person reference units and three different sources. The 1994 observation they use is not included in our series because it does not properly define the type of income it uses. This lack of information accounts for the WIID considering the observation as not reliable (NOOK) and we do not use it. ${ }^{8}$

Nevertheless, the grouping procedure of DS has been strongly criticized by AB. Using a sample of OECD countries; they show how inconsistent it is to create such series. In many cases the constructed DS-accept series significantly modify the level and even the trend of some inequality series, in comparison with series that use only consistent income concepts. Furthermore, AB demonstrate for OECD countries, that the use of dummy variables is not enough to render some definitions comparable. In particular this is the case for net and gross income, as well as for income based and expenditure based observations.?

DS defend the grouping of net and gross income by assuming that in developing countries, where there is not enough data to compare both definitions, redistribution is not important and thus, gross and net income are comparable. Yet, $\mathrm{AB}$ stress the inconsistencies this mixing yields for many OECD countries for which both types of income are available. Compared with the Luxembourg Inequality Study (LIS), which adjusts inequality data to make it international comparable within the OECD countries (Atkinson, et al., 1995), AB find that the rankings provided by DS are very different from those of the LIS. Similarly, for the case of expenditure-based and income-based observations, DS acknowledge that both concepts are significantly different. To correct for this problem, they suggest the use of a fixed adjustment to render both concepts comparable. In their dataset they find that expenditure-based observations are on average 6.6 points below income-based Gini coefficients. However, this particular value is conditional on the sample they analyze. We use the same procedure and compare the inequality levels of both concepts only for those countries where both are available, but in our sample we find that the average difference is three points. ${ }^{10}$ Therefore, using the fixed value proposed by DS increases on average, around 3.6 points the levels of inequality for the countries in our sample. We conclude that the estimate of the true difference

\footnotetext{
${ }^{8}$ For the rest of the MIDEPLAN observations, they are not DS-accept because there was not a clear reference to the primary source. However, WIID consider this data to be reliable and it provides more observations to be used.

${ }^{9}$ In the next section, we use a bigger sample and reach similar conclusions.

10 The sample difference is given by the larger compilation provided by the WIID and by the differences in some of the quality criteria we explained before. In our case, we can directly compare 19 countries that have both income and expenditure information, of which $58 \%$ belong to the OECD.
} 
can be unreliable and the use of fixed adjustments introduces arbitrary noise in an already problematic dataset. In short, we agree with $\mathrm{AB}$ and conclude that the use of fixed adjustments is not enough to reconcile both definitions.

The treatment of different reference units by DS is also problematic. DS collapse the numerous definitions into two categories: person-based and household-based observations. After this rough grouping, they compare both definitions and conclude that they are not significantly different. However, not all the person-based definitions are comparable, nor are all the household-based ones. This raises additional questions about their comparability assumptions.

Table 1: Chile, Gini series with different definitions, 1968-1996

\begin{tabular}{|c|c|c|c|c|c|c|c|c|}
\hline Income & \multicolumn{6}{|c|}{ Gross Income } & Monetary & \multirow{4}{*}{$\begin{array}{c}\text { DS accept } \\
(8)\end{array}$} \\
\hline Recipient: & \multicolumn{3}{|c|}{ Household } & \multicolumn{3}{|c|}{ Person } & Household & \\
\hline Source: & UN & Fields & SH & Mideplan & Paukert & IADB & $\mathrm{SH}$ & \\
\hline Series: & (1) & $(2)$ & (3) & $(4)$ & (5) & $(6)$ & $(7)$ & \\
\hline 1968 & 45.64 & & & & 44.00 & & & 45.64 \\
\hline 1969 & & & & & & & & \\
\hline 1970 & & & & & & & & \\
\hline 1971 & & 46.00 & & & & & & 46.00 \\
\hline 1972 & & & & & & & & \\
\hline 1973 & & & & & & & & \\
\hline 1974 & & & & & & & & \\
\hline 1975 & & & & & & & & \\
\hline 1976 & & & & & & & & \\
\hline 1977 & & & & & & & & \\
\hline 1978 & & & & & & & & \\
\hline 1979 & & & & & & & & \\
\hline 1980 & & & & 53.21 & & & & 53.21 \\
\hline 1981 & & & & 53.46 & & & & \\
\hline 1982 & & & & 56.98 & & & & \\
\hline 1983 & & & & 54.49 & & & & \\
\hline 1984 & & & & 55.85 & & & & \\
\hline 1985 & & & & 54.91 & & & & \\
\hline 1986 & & & & 55.69 & & & & \\
\hline 1987 & & & & 56.72 & & & & \\
\hline 1988 & & & & 54.50 & & & & \\
\hline 1989 & & & & 57.88 & & & & 57.88 \\
\hline 1990 & & & 54.70 & 53.18 & & & 55.65 & \\
\hline 1991 & & & & 55.38 & & & & \\
\hline 1992 & & & 52.19 & 50.70 & & 52.00 & 53.08 & \\
\hline 1993 & & & & & & 50.00 & & \\
\hline 1994 & & & 55.58 & & & & 57.42 & 56.49 \\
\hline 1995 & & & & & & & & \\
\hline 1996 & & & 56.37 & & & & 57.24 & \\
\hline
\end{tabular}

Note: Observations in boxes represent data with grouped data information

Source: WIID, version 1, Sept. 2000 
We use two examples to highlight in detail the main problems involved when grouping heterogeneous series. In Figure 1 we plot two inequality series for Spain, each differs in the concept measured (e.g. gross income and expenditure). Each series has different levels and no significant trend. However, DS use two gross income observations to expand the expenditure series and this alters significantly the inequality conclusions. First, the DS series has an apparent time trend, with a considerable decrease in inequality from the 1970s to the 1980s. Secondly, the combination of both concepts significantly changes the inequality levels. In particular, the gross income series for the 1980s yields inequality observations of around 8 points higher than the DS-accept values. Such a dramatic level variation substantially changes the country's international inequality ranking, as we show in Section 5.

In Figure 2 we plot two series for Mexico that differ in their reference unit (household and person), but have the same gross income concept. Both series have distinctive time trends and significantly different levels in the last years. DS combine both reference units and again, freely mixing different definitions changes the inequality results. In particular, for the 1980s, the levels of both series are quite different -around 8 points- and this introduces an important change to the apparent inequality pattern. Furthermore, DS report an increase in inequality from 1977 to 1989, while the consistent gross-household series shows the opposite result. Finally, the DS dataset fails to indicate any time trend at all for the entire period, while the gross-household series has, at least, a decreasing trend.

Although such examples are not widespread, they certainly introduce noise in the data that increases the measurement error and may affect the overall empirical results. While the corrections proposed by DS may sometimes work, on other occasions they may distort the data further or leave the discrepancies unaltered. In our last example from Mexico, DS do not recommend any correction for reference unit differences and the problem shown above persists. 
Figure 1: Spain, Gini coefficient series

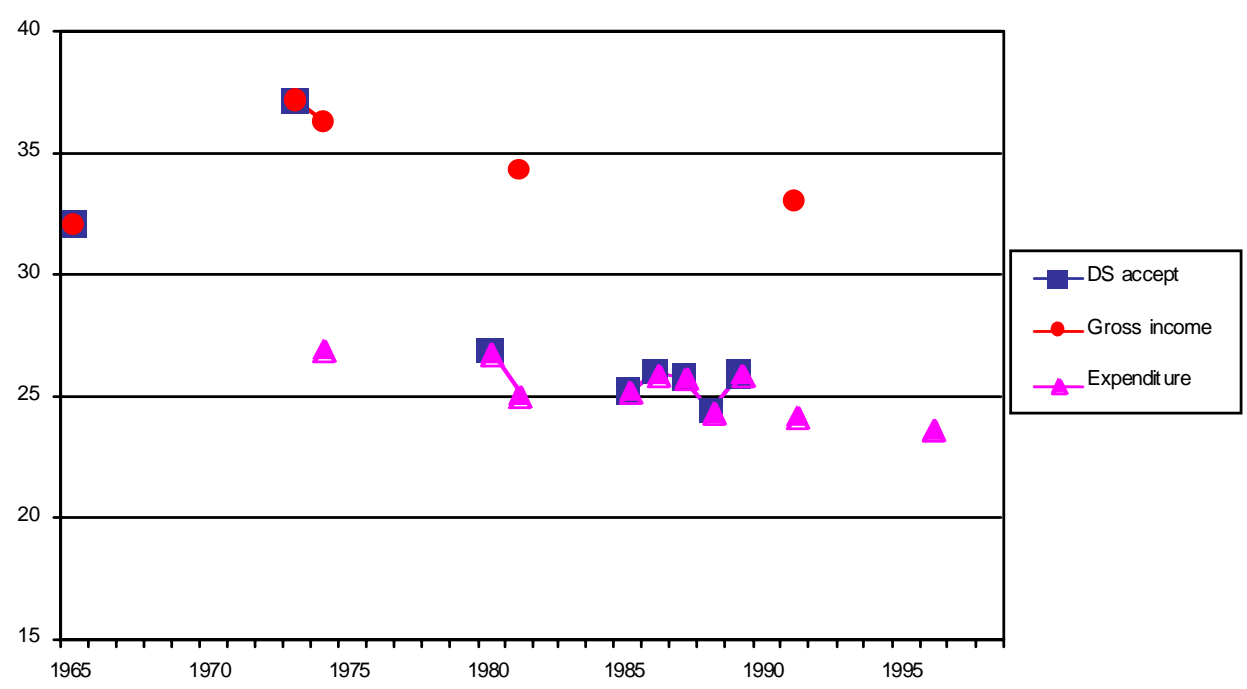

Figure 2: Mexico, Gini coefficient series

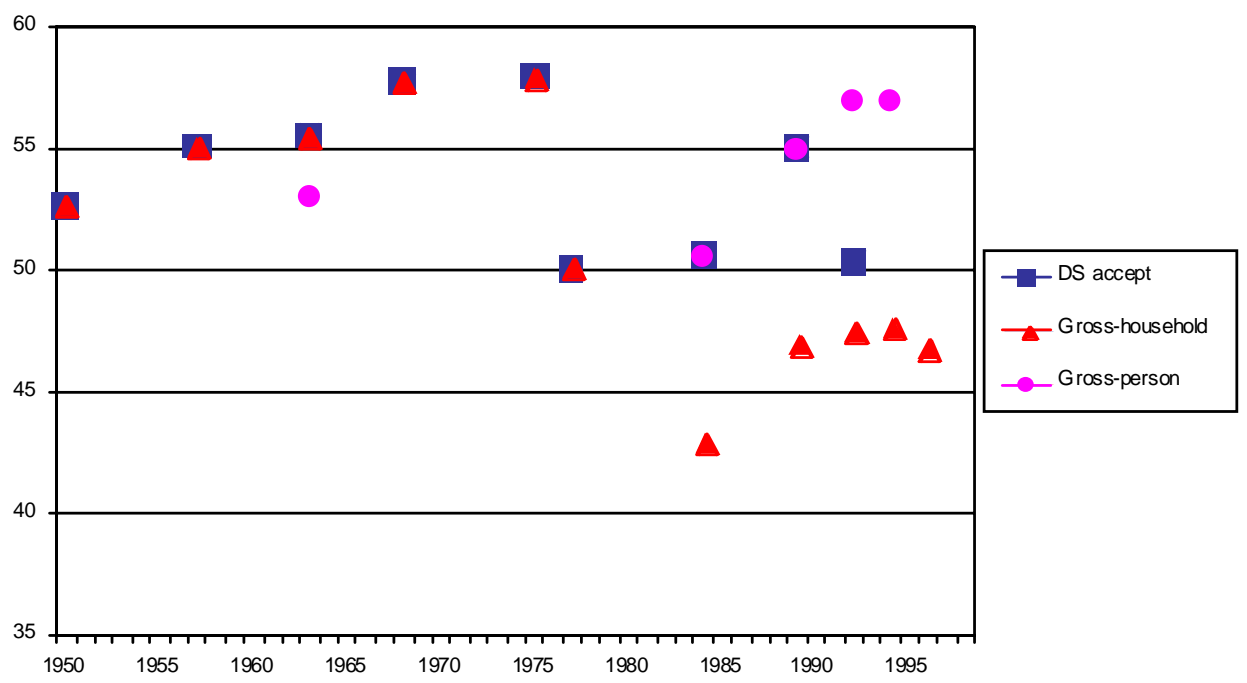

For the case of Spain, the use of the particular 6.6 adjustment value reduces the inconsistencies, but in other cases it does not help.

In summary, although the DS dataset was a very important step forward in the study of inequality data, it has significant limitations that increase the measurement error and may seriously 
alter the empirical results of those studies that use this inequality dataset. In particular, though it is quite reasonable to use the kind of quality control considerations they introduced, the evidence suggests that grouping different definitions to create single country time series is unreliable and the use of fixed adjustments does not correct this problem.

\section{Controlling for definition comparability and series grouping}

Since there are several concepts and reference units, we still would like to have a methodology for collapsing the various series available for each country. This is necessary to obtain consistent and comparable series that can be used in cross-country and time series studies. To collapse further the existing series provided by the WIID, we take three steps. First, we group those series which have the same definitions (concept and reference unit). The second step is to make a comparability analysis and judge which definitions and conflicting sources can be mixed and how. The final step is to construct the national series, using consistent groupings and standard procedures based on these results.

\subsection{Grouping series with the same definitions}

It is straightforward to group those series with identical definitions. The main difficulty in this first step is to deal with different sources. In some cases, we can have a year where two sources report observations with the same definitions. This is the case for Chile in 1992, shown in series 4 and 6 of Table 1. If both sources have series that can be analyzed ${ }^{11}$ we run the same comparability tests as below. If this is not possible, we choose observations using the following preference ordering:

1. Observations with income share information

2. LIS data

3. DS accept data

4. The source with the longest time coverage.

Since one of our main purposes is to compare the Gini coefficient with alternative indexes, we need the income share information to construct such indexes. The Luxembourg Income Study (LIS) is a project that has created a micro-data of social and economic information. It has been used to

${ }^{11}$ As explained below, this requires that both series have a common sample of at least three observations in a time span of five or more years. 
explicitly compare cross-country inequality information and thus presents adjusted data for such purposes. Finally, the last two ordering preferences ensure consistency in the series and the previous considerations contemplated by DS.

In our example for Chile, we have two conflicting sources: MIDEPLAN and IADB. Using the decision criteria stated before we prefer the MIDEPLAN observation, since it provides income share information. After doing this first grouping, we have collapsed seven series into three (see Table 2).

We use the same standard procedure with all the countries to collapse series with the same definitions. However, this first step is insufficient given that many countries remain with several series (i.e. Sweden has up to 14) and further grouping procedures are necessary.

\subsection{Comparability analysis}

Li et al. (1998) have compared values of the Gini coefficient with different definitions for countries and years where estimates are available. However, this procedure is biased towards the sample of countries with available data. A more satisfactory procedure is to compare observations available for the same country and the same year, as was done by DS.

The existing literature does not offer a consistent and standard comparison procedure. DS limit themselves to comparing the average difference between different definitions. In the case of income and expenditure, they try to check the correlation of the differences with some explanatory variables. There are problems with this approach. For two series to be comparable, and thus, interchangeable if one data observation is missing, we need much more than average differences. We need two series that have a very similar trend and level. In the case the level is not comparable, we need the difference between both series to be relatively constant over time and only in such cases does it makes sense to freely mix different series. In other cases, grouping definitions that are not comparable can seriously alter the level and/or trend of the series. Adjusted data in this way at best increases the measurement error and at worst can invalidate the empirical results.

In addition, to clearly single out what we are comparing, the series should differ in only one of the definitions. For example, if a Gini coefficient series for net income and household seems comparable with a series of gross income and person, it could be because indeed gross and net are comparable or because net and gross are different but a combination of income concepts and reference units produce the similarities. 
Table 2: Chile, grouped Gini series, 1968-1996

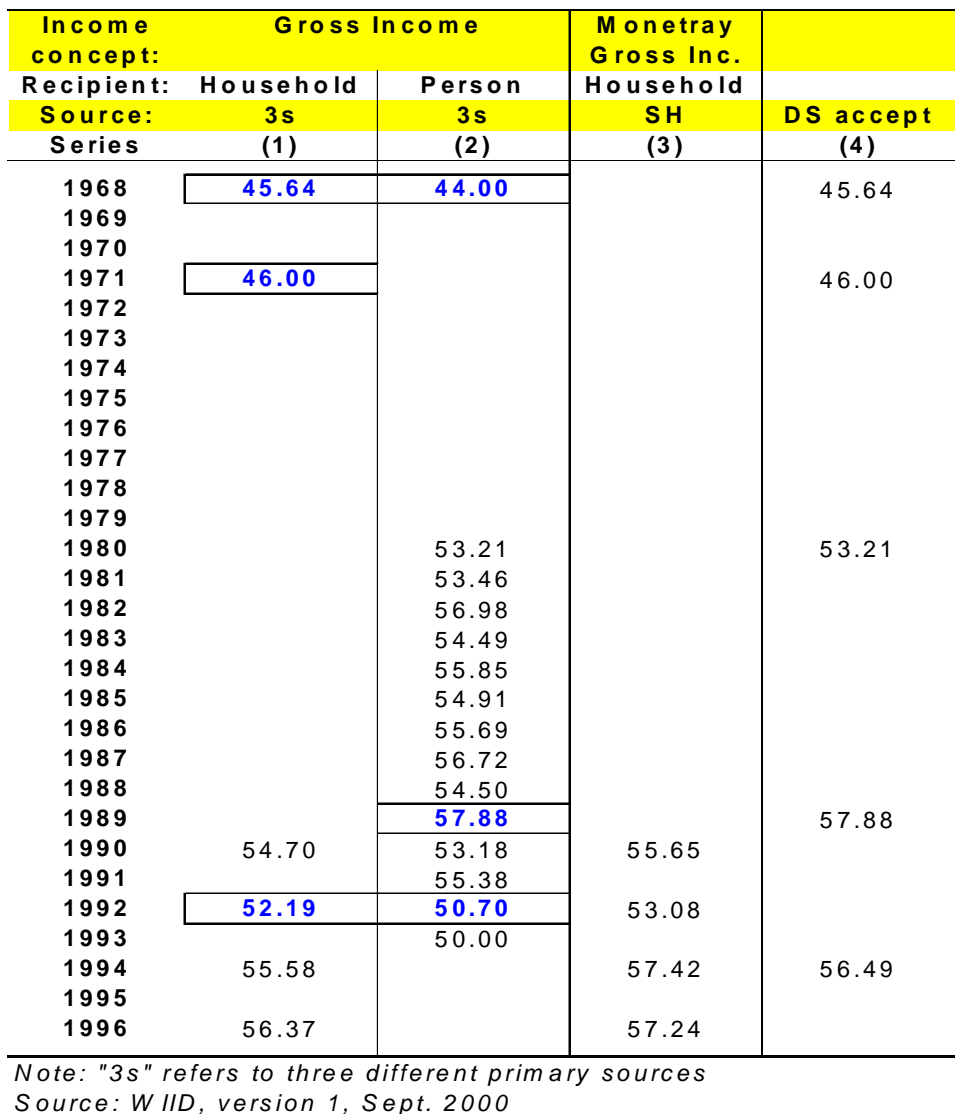

\subsection{Comparability criteria}

To analyze different definitions and sources, we use the following procedure:

- Use only Gini data for the same country and the same year when they differ in only one of the definitions (concept or reference unit) and have a common sample of at least three observations in a time span of at least five years.

- Estimate the simple correlation between both series. If the correlation is negative we conclude that the series are not comparable.

- Check if both series are normally distributed and run hypothesis tests for equal mean and equal variance (i.e. a t-test and an F-test). If the variance is significantly different (at a 5\% 
significance level) then we conclude that the series are not comparable. If the mean is significantly different, we test if there is a constant difference between them. ${ }^{12}$

- When the series are positively correlated and have a similar variance, they move in the same direction over time. If instead, the mean is not equal we use the average difference between series. ${ }^{13}$ Furthermore, we check for one, three and five points differences in the means (which are some values reported as the average difference between series with different concepts).

- To complement the hypothesis of equal mean and variance, we take OLS regressions on the equation: $S_{1}=\beta\left(S_{2}+c\right)+\varepsilon$, where $S$ represents the series and $\varepsilon$ the error term. When the means of $S_{1}$ and $S_{2}$ are not the same $c$ is the average difference of the series, otherwise $c=0$. We run a Wald coefficient test to check the null hypothesis that $\beta=1$. To check how sensitive the series are to absolute differences in the mean, we also test the null hypothesis when $c$ is $\pm 1,3$ and 5 . Note that in this case the inclusion of $c$ is equivalent to the use of a fixed adjustment or the use of a dummy variable.

- In summary, we consider two series to be comparable when they have a positive correlation, not a significantly different variance and we cannot reject the null hypothesis that $\beta=1$, when $-1 \leq c \leq 1$. For other values of $c$ we consider the series to be comparable, but with a constant absolute difference between them. In this last case, we must add $c$ to make the series compatible.

Through this comparison procedure we attempt to assure that both series have statistically the same time trend and the same level (or an absolute constant difference). This helps ensure that when freely mixing two series we do not alter the trend or level of the resulting series. ${ }^{14}$

\subsection{Comparability assumptions}

Once we have pared comparable series and followed the previous procedure, we can study which definitions can be mixed. The results of this analysis provide the basis for establishing the

\footnotetext{
${ }^{12}$ For the few cases where the series fail the test of being normally distributed, we use the ANOVA F-statistic to test for equality of means and the Levene and the Brown-Forsythe methods to test for the equality of the variances. Again, if the variance is significantly different we conclude that the series are not comparable.

${ }^{13}$ We round the values to the closest integer to simplify the procedure. In some cases we need to use half points in order for the series to be comparable.

14 This procedure was also employed to compare some series that differed only in the source.
} 
comparability assumptions we use later, which allows us to consolidate series and reduce the number of definition combinations available for each country. In total we have 179 comparable pairs for 38 countries, 14 of which are OECD countries with 107 pairs and 24 are developing countries with 72 pairs. The results for all the comparable definitions are summarized in Table 3.

In the table, the first column shows which variables are being compared. The next two columns indicate the number of pairs compared and the percentage that belongs to OECD countries. The next column is very important, since it shows the percentage of series that are not comparable, either because there is a negative correlation between the series or because they fail the equal variance test. The columns labeled $c \pm 1$ and $c \pm 2$ show the percentage of comparable series when the absolute average difference is less than one and two, respectively. The following column shows the sample average difference and the next column reports the percentage of series that are comparable when this average difference is applied. The final column indicates the decision regarding the comparison of definitions.

In Table 3 we show all the 11 possible comparisons. We analyze below the six most relevant pairs and we use them to illustrate how we reach the final decision regarding the comparability assumptions. The remaining five couples follow the same procedure and we just mention the final decision. Three main considerations were taken into account when deciding which series could be comparable. The first criterion was the percentage of non-comparable couples. A high percentage indicates that the considered series had different trends and hence, provide a very bad substitute for a missing series. The second criterion is the percentage of comparable series when no fixed adjustment is applied and when the average difference is applied. These percentages show how good it can be to mix series with or without a fixed adjustment. Finally, we prefer combinations with large samples and, for some cases; the percentage of OECD observations is also relevant for the analysis.

Income and Monetary Income. In this case, we have four developing countries and the USA, which offer seven comparable pairs. Of these, $43 \%$ are comparable series with an average difference $(c)$ smaller than \pm 1 and $71 \%$ are in the range of $c<|2|$. Almost one third of the pairs are comparable when using the average difference of -2 . Moreover, all the pairs are positively correlated and have an equal variance.

This result is theoretically consistent, since monetary income excludes own-produced consumption and it should report a higher level of inequality. Since all the series are in principle comparable it seems reasonable to freely mix both definitions. Nonetheless, we are uncertain of 
which fixed adjustment (average difference) to apply. If we use the average difference of -2 only $29 \%$ of the series are comparable. Another inconvenience is the small sample of only seven observations. Thus, we are uncertain about this comparison couple.

Table 3: Comparability results for all definitions

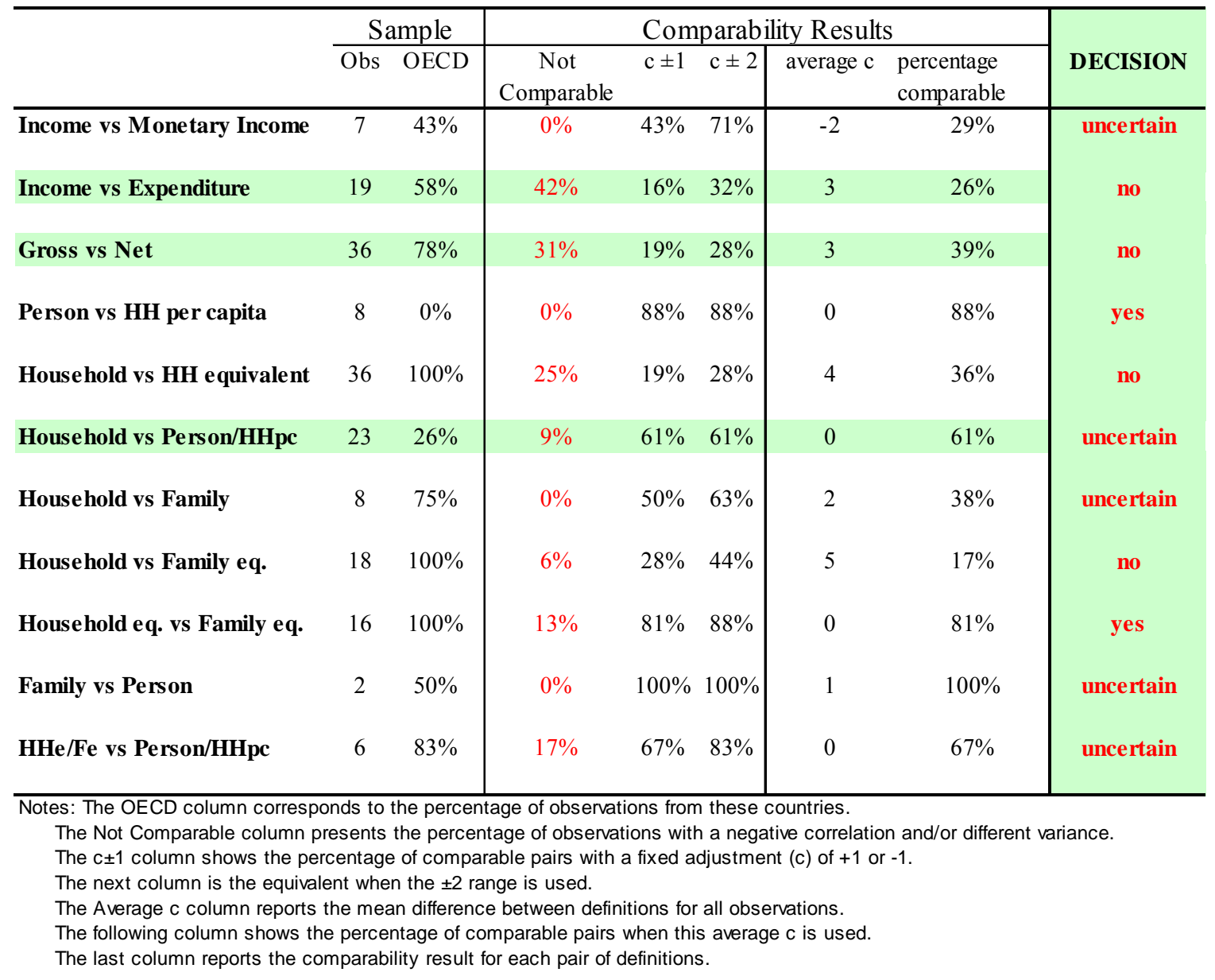

It is important to note that DS did not take into consideration data observations defined for monetary income. They argue that the consumption of own produced goods is an important source of revenue for poorer households and not taking into account this kind of consumption can skew the indicator towards more inequality. However, our results suggest that for some cases, a fix adjustment can render both definitions comparable. In particular, we mix both definitions only in rich and middle-income countries ${ }^{15}$, for which one does not expect this kind of consumption to be

\footnotetext{
15 Australia, Brazil, Costa Rica, Hong Kong, Panama, Russia, United States and Venezuela.
} 
important. Therefore, we find it reasonable to include data based on monetary income for these countries and by doing so we can expand the available number of observations.

On the other hand, the example provided by DS to exclude monetary income is not compelling. Although later they conclude, as we do, that income and expenditure-based are not readily comparable, in their paper they actually compare the monetary income and expenditure observations for Greece in 1974, as a way to associate income and monetary income. Since for this year the difference in both series is of roughly six points they conclude that both definitions cannot be mixed. However, when applying our comparability analysis to Greece, we conclude that both series are indeed comparable when adding three points to the expenditure series.

Income and Expenditure. In this case $42 \%$ of the observation couples are not comparable at all, i.e., they have a negative correlation or significantly different variance. Moreover, if we were to use a fixed adjustment to compare series, only $26 \%$ are comparable for the average difference of 3 points. If we were to use the average difference found in DS of 6.6 , then only $11 \%$ of the series are comparable. In other words, in almost one out of ten cases this particular fixed adjustment significantly alters the level and/or trend of the series, overwriting information contained in the original data.

Since expenditure does not take into account income that is saved, we expect it to give less unequal values. Moreover, expenditure information can take into account income smoothing by borrowing or lending. Thus, we also expect lower inequality values from expenditure surveys. ${ }^{16}$

However, we find it highly problematic to freely mix expenditure-based and income-based inequality observations. Given the very high percentage of non-comparable cases, the most likely possibility is that both series are providing different inequality information. Therefore, we conclude that it is not reasonable to mix income and expenditure definitions, not even when using fixed adjustments.

Gross and Net Income. For this case, almost a third of all the series couples are not comparable. The average difference is of three points, but only $39 \%$ of the series are comparable when such a

\footnotetext{
16 In developing countries expenditure surveys are prevalent since many households do not know their actual income or their knowledge is incomplete. This can be explained by the presence of significant own-produced consumption, temporal and/or irregular monetary income sources. Therefore, it is easier to survey their consumption (expenditure) and this has become a common practice in poor countries.
} 
fixed effect is applied. Although this is not such a clear case as the previous, we also reject comparing gross and net income. One argument used in DS to compare both definitions is that in developing countries the difference should not be big, assuming that their redistribution systems have a small impact on incomes. However, of the eight comparisons that come from non-OECD countries, $25 \%$ are not comparable, $50 \%$ are comparable with $c<|1|$ and $38 \%$ are comparable when the average difference of three points is applied. Therefore, even when the sample is still small and all the non-OECD countries involved are middle-income countries, there is not much evidence that gross and net income are equivalent.

On the other hand, grouping series with net and gross income does make a significant impact in OECD series. In particular, $\mathrm{AB}$ show in detail how damaging the combination of both definitions is to the information on levels and trends contained in the original series for these rich countries.

Mixing different reference units. Grouping person and household per capita is probably the clearest case in favor of mixing definitions. In $88 \%$ of the cases we can freely mix both series. In addition, we do not need to adjust for any fixed effects. Although the sample of eight is small, the evidence is strong. Therefore, we assume that both series are comparable and we evaluate this combined definition (person-household per capita) with other income recipient definitions.

On the other extreme, comparing household and household equivalent observations does not seem reasonable. A quarter of the observations are not comparable and when the average difference of four points is applied only $36 \%$ of the series are comparable.

The comparability of household with person/household per capita is an uncertain one. The non-comparable percentage is relatively small, but only in $61 \%$ of the cases are the definitions comparable. In fact, household and person are the most common reference units and this particular comparability assumption is very important and we deal with it latter.

The remaining five comparability results regarding reference units are shown in Table 3 . In summary, for the eight couple of reference unit definitions that were tested, only one was clearly non-comparable. These results suggest that one may mix reference units in many cases, but not in all.

\subsection{Grouping the data}

Using the results of the previous section we can directly group those series with comparable definitions and reduce the number of series per country. However, since the three main concepts (e.g. net income, gross income and expenditure) cannot be mixed, then inevitably we have more 
than one inequality series for some countries. Moreover, we associate each concept with the most common reference unit and this union creates our three main resulting series: gross incomehousehold, net income-household and expenditure-person.

The presence of three series may seem inconvenient when conducting empirical research, but different income concepts may offer different information about inequality behavior and using more than one concept can increase the available information that we can use. For example, evaluating both gross and net income inequality measures provides important information concerning the redistribution policies of some national governments. In addition, trade theory makes direct predictions about gross, not net factor incomes.

On the other hand, separating series because of different reference units is not very compelling. Any difference provided by dissimilar reference units are mostly explained by demographic factors. When the size of the household changes according to the income classes, one can expect different inequality results from household and individual information. In addition, the number of adults in different income classes can provide divergences in the inequality results. However, these demographic factors vary across countries.

An additional advantage of our comparability analysis is that it offers country-specific information. For those countries were we conducted the tests, we have and indication of whether specific national series with different definitions may be comparable or not. This information is used to group series in that particular country, even if the overall analysis resulted in a verdict of noncomparable definitions. For instance, in a country were gross and net income are comparable with a fixed adjustment, we can use this information to expand one or both series.

Finally, we have to take a decision concerning those definitions that yield an uncertain result. The approach we take is to have two broad types of series. First, we construct "basic" series in which we are confident of the definition groupings used. Hence, we only mix definitions for which we have strong evidence that they may be comparable and/or definitions that are comparable for that particular country.

We then construct "extended" series. These series have more observations, but we use definition groupings that are less reliable and we combine definitions for which we are uncertain about their comparability. For example, the most common "basic" series is the data based on gross income and household definitions, and this series is mostly complemented with observations based on monetary income and person definitions to create the "extended" series. 
In summary, to finally collapse the remaining series, we perform the following standard procedure:

- Group those reference units for which we are certain about their comparability

- Use the country specific information to further group series. In particular, to expand the most common series: gross income-household, net income-household and expenditureperson. This includes grouping series with a fixed adjustment, when the evidence supports this type of comparability assumption. ${ }^{17}$

- Take advantage of the LIS data (only available for OECD countries) to adjust the series in those cases in which they are comparable. E.g., if we have a net income-household series from both the LIS and another source, and both series are comparable with a fixed adjustment, then we adjust the series to have the levels reported by the LIS data.

- Finally, we use definitions for which we are uncertain about their comparability to create the "extended" series.

In brief, for each country we can have one or more basic series relating to gross income, net income or expenditure and in some cases, extended series, which expand these series by including uncertain definition comparisons.

Even though we apply the same procedure for each country and in every case we try to be as objective as possible, we face the same dilemma expressed by DS and "decisions concerning the inclusion or exclusion of certain observations are always based on some judgment and arbitrariness".

In our case, our results can be replicated using the WIID database. ${ }^{18}$ This allows other researches to review our procedure and make their own changes if necessary.

Using our previous example for Chile, from an initial number of seven series, we can collapse the inequality information into two "basic" series (see Table 4). Here we used the fact that for Chile

${ }^{17}$ When some observations are adjusted to make them consistent with the rest of the series, we have a problem with the Atkinson indexes (which we calculate later). Generally, the discrepancy between Gini coefficients with different definitions is not the same than for the Atkinson indexes. To solve this problem we use two standard approaches. A direct approach is applied when we have three or more comparable Atkinson observations and then, we directly apply the average difference. The indirect approach is to estimate the average difference between Gini and the particular Atkinson index for both series and then adjust the Atkinson by the difference between both averages.

${ }^{18}$ Our inequality dataset is posted in the web and there we present the country-specific adjustments made and the GAMS code used later (www.intereconomics.com/francois/data.html). 
the household and person series are comparable with an adjustment of 1.5 points. This allows us to expand the gross income-household series from 6 to 15 observations. ${ }^{19}$

When compared with the DS accept series the levels are not significantly different, but in this example, we find different time trends. In section 4 we compare in detail the inequality trends reflected in our dataset against those present in the DS dataset.

\subsection{Characteristics of the three main series}

When our grouping methodology is applied to all the countries, we still have several series, especially in OECD countries. However, the three main series have comprehensive world coverage and can be readily used for empirical analysis. The main statistics of these series are presented in Table 5.

Although all the series have a smaller sample and coverage than the DS-accept series, we still have a satisfactory representation. Moreover, the extended gross-household series is fairly comparable in number of observations and OECD representation to the DS-accept series.

The net-household series seems to be better suited to analyze OECD countries, while the expenditure-person series consists of a majority of developing countries. The gross income series is better balanced between rich and poor countries. These sample differences between concepts can also be observed in the average series length. OECD countries have longer series and this is reflected in the average number of observations in the net income series. In contrast, developing countries and the expenditure-person series have shorter series, and in many cases just one or two observations.

Additionally, we have at least one of the three main series for 145 countries. This is an improvement with respect to the 115 country coverage of the DS dataset. The share data is also sparser than the Gini coefficient observations and again, only the net income series has almost the same number of share data and Gini observations, due to the better quality of the OECD inequality data.

\subsection{Series length and panel data analysis}

Another important issue concerns the length of the series we choose to analyze. Given the sparse amount of inequality information in many countries, once we have created the basic and extended

\footnotetext{
${ }^{19}$ Note that for international comparisons we only use the first series. The second series is only used when analyzing inequality in Chile.
} 
series, some countries end up with only one or two data points per series. Subsequently, when we analyze inequality trends and when we compare our dataset with DS, we use only countries with at least one series with three or more observations, in a time span of at least five years. This allows us to study cross-country inequality trends and use panel data analysis. This set of countries with long series includes 80 countries and the main characteristics are reported in Table 6 . In the Appendix we present the summary statistics of this subset of countries with longer series.

Table 4: Chile, final Gini series, 1968-1996

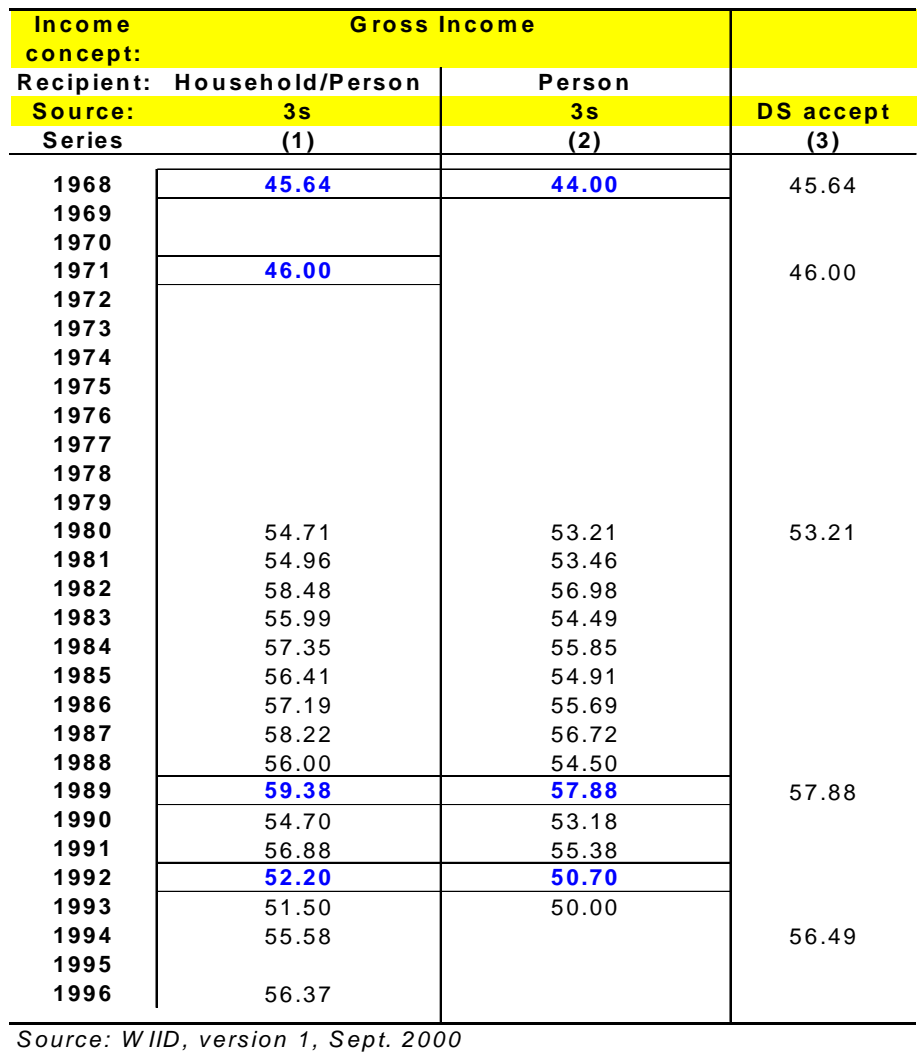


Table 5: Characteristics of the three main inequality series

\begin{tabular}{|c|c|c|c|c|c|c|c|c|c|}
\hline & \multicolumn{2}{|c|}{$\begin{array}{c}\text { Gross Income } \\
\text { Household }\end{array}$} & \multicolumn{2}{|c|}{$\begin{array}{c}\text { Net Income } \\
\text { Household }\end{array}$} & \multicolumn{2}{|c|}{$\begin{array}{c}\text { Expenditure } \\
\text { Person }\end{array}$} & \multicolumn{2}{|c|}{$\begin{array}{l}\text { Total for the } \\
\text { three series }\end{array}$} & \multirow[t]{2}{*}{ DS-accept } \\
\hline & Gini & $\begin{array}{c}\text { Share } \\
\text { data }\end{array}$ & Gini & $\begin{array}{c}\text { Share } \\
\text { data }\end{array}$ & Gini & $\begin{array}{c}\text { Share } \\
\text { data }\end{array}$ & Gini & $\begin{array}{c}\text { Share } \\
\text { data }\end{array}$ & \\
\hline \multicolumn{10}{|l|}{ BASIC series } \\
\hline Countries & 49 & 38 & 27 & 25 & 69 & 63 & 145 & 126 & 115 \\
\hline Observations & 427 & 326 & 288 & 241 & 189 & 159 & 904 & 726 & 693 \\
\hline Average obs. & 8.71 & 8.58 & 10.67 & 9.64 & 2.74 & 2.52 & 6.23 & 5.76 & 6.03 \\
\hline OECD countries & $29 \%$ & $39 \%$ & $70 \%$ & $72 \%$ & $1 \%$ & $2 \%$ & $23 \%$ & $27 \%$ & $17 \%$ \\
\hline \multicolumn{10}{|l|}{ EXTENDED series } \\
\hline Countries & 95 & 70 & 47 & 43 & 85 & 75 & 227 & 188 & 115 \\
\hline Observations & 634 & 445 & 433 & 376 & 254 & 205 & 1321 & 1026 & 693 \\
\hline Average obs. & 6.67 & 6.36 & 9.21 & 8.74 & 2.99 & 2.73 & 5.82 & 5.46 & 6.03 \\
\hline OECD countries & $17 \%$ & $23 \%$ & $43 \%$ & $44 \%$ & $1 \%$ & $1 \%$ & $16 \%$ & $19 \%$ & $17 \%$ \\
\hline
\end{tabular}

Table 6: Characteristics of the three main inequality series, countries with three or more observations

\begin{tabular}{|c|c|c|c|c|c|c|c|c|c|}
\hline & \multicolumn{2}{|c|}{$\begin{array}{c}\text { Gross Income } \\
\text { Household }\end{array}$} & \multicolumn{2}{|c|}{$\begin{array}{c}\text { Net Income } \\
\text { Household }\end{array}$} & \multicolumn{2}{|c|}{$\begin{array}{c}\text { Expenditure } \\
\text { Person }\end{array}$} & \multicolumn{2}{|c|}{$\begin{array}{l}\text { Total for the } \\
\text { three series }\end{array}$} & \multirow[t]{2}{*}{ DS-accept } \\
\hline & Gini & $\begin{array}{c}\text { Share } \\
\text { data }\end{array}$ & Gini & $\begin{array}{c}\text { Share } \\
\text { data }\end{array}$ & Gini & $\begin{array}{c}\text { Share } \\
\text { data }\end{array}$ & Gini & $\begin{array}{c}\text { Share } \\
\text { data }\end{array}$ & \\
\hline \multicolumn{10}{|l|}{ BASIC series } \\
\hline Countries & 38 & 34 & 20 & 20 & 22 & 21 & 80 & 75 & 66 \\
\hline Observations & 413 & 322 & 279 & 235 & 127 & 106 & 819 & 663 & 634 \\
\hline Average obs. & 10.87 & 9.47 & 13.95 & 11.75 & 5.77 & 5.05 & 10.24 & 8.84 & 9.61 \\
\hline OECD countries & $37 \%$ & $47 \%$ & $75 \%$ & $75 \%$ & $5 \%$ & $5 \%$ & $38 \%$ & $43 \%$ & $29 \%$ \\
\hline \multicolumn{10}{|l|}{ EXTENDED series } \\
\hline Countries & 57 & 47 & 32 & 31 & 30 & 28 & 119 & 106 & 66 \\
\hline Observations & 580 & 420 & 407 & 354 & 182 & 146 & 1169 & 920 & 634 \\
\hline Average obs. & 10.18 & 8.94 & 12.72 & 11.42 & 6.07 & 5.21 & 9.82 & 8.68 & 9.61 \\
\hline OECD countries & $26 \%$ & $32 \%$ & $50 \%$ & $52 \%$ & $13 \%$ & $11 \%$ & $29 \%$ & $32 \%$ & $29 \%$ \\
\hline
\end{tabular}

Our full dataset, which includes countries with only one or two observations, can be used to conduct cross-country analysis for specific years. It also allows for decade or five year averages that can be used as a panel database. Since there is a majority of expenditure-person series for developing countries in the full dataset, this can give a better representation than the longer series.

In summary, we have six main series: three basic series, with consistent definition comparability and three extended series with less reliable comparability assumptions. In constructing these series, we have used the recommendations made by Atkinson and Brandolini (2001):

"The use of simple dummy variable adjustments for data differences is not appropriate.

Over time, the net and gross income distributions may behave differently, as may the distributions for households and for families. It is necessary to piece together 
information from different sources, informed by an awareness of their relative strengths and weaknesses. All of this points to the need for a blend of quantitative and qualitative analysis, and the avoidance of mechanical use of the (secondary) datasets."

\section{Alternative inequality indexes}

We now turn our attention to a different topic. In this section we estimate Lorenz curves from grouped income data. This allows us to re-estimate Gini coefficients, compute the Atkinson indexes and estimate headcount poverty ratios.

Thereafter, we can use these estimates to conduct some tests. First, we compare our Gini estimates, which are drawn from the Lorenz curve, with the Gini coefficients reported by the primary sources. Secondly, we test if the inequality information provided by the Gini coefficient is similar to the one offered by the Atkinson indexes. The later can be considered a test of the robustness of the Gini coefficient as an inequality indicator.

\subsection{Inequality measurement}

Most of the inequality observations provided by the secondary datasets are given by Gini coefficients. Formally, this inequality measure is given by:

$$
\mathrm{G}=1+\left(\frac{1}{\mathrm{n}}\right)-\left(\frac{2}{\mathrm{n}^{2} \mathrm{y}}\right)\left(\mathrm{y}^{1}+2 \mathrm{y}^{2}+\ldots+\mathrm{ny}^{\mathrm{n}}\right)=1+\left(\frac{1}{\mathrm{n}}\right)-\left[\frac{2}{\mathrm{n}^{2}} \sum_{h} \frac{h y^{h}}{\bar{y}}\right]
$$

where $y^{b}$ is the income of household $h$ and income is arranged so $y^{1} \geq y^{2} \geq \ldots \geq y^{n} ; n$ is the number of households and $\bar{y}$ is the average income. Although this inequality index is widely accepted and used, there are many other inequality indexes and there is no theoretical prerogative to prefer any.

Inequality is associated with the variance of the income distribution and this creates two basic measurement complications. First, as with any distribution, it is not a single-valued variable. Second, even when the concepts of Lorenz-dominance and Generalized Lorenz-dominance (Shorrocks, 1983) are widely accepted as ways to impartially rank two different distributions, in many cases the Lorenzcurve intersects at least once, and this method yields an incomplete ranking of distributions.

To solve both problems, inequality indexes are used to rank distributions in these indeterminate cases and to provide a single-valued variable that can be used in empirical models. However, since all 
inequality indexes have a specific method to weight and rank incomes from different levels, there is no objective inequality index and any inequality indicator has built-in social preferences. Moreover, many inequality measures are implicitly based on a social welfare function. ${ }^{20}$

In particular, when the Lorenz curves intersect, different indexes can provide different inequality information and this makes the choice of the index important for the results. For instance, the Gini coefficient is more sensitive to changes in the middle of the income distribution and it is less sensitive to movements at the extremes. On the contrary, the family of Atkinson indexes is precisely more sensitive to changes at the extremes and thus, it is a very convenient complement to the Gini coefficient.

Formally, the Atkinson index $(A)$ is defined as:

$$
A=\left\{\begin{array}{c}
1-\left[\frac{1}{n} \sum_{h}\left(\frac{y^{h}}{y}\right)^{1-\theta}\right]^{\frac{1}{1-\theta}} \quad \text { if } \theta \neq 1 \\
1-\prod_{h}\left(\frac{y^{h}}{\bar{y}}\right)^{\frac{1}{n}} \text { if } \theta=1
\end{array}\right.
$$

where the level of sensitivity is conveniently provided by the inequality aversion parameter $(\theta)$, which defines each Atkinson index.

To illustrate the differences between both inequality measures, in Figure 3 we plot the Lorenz curves for Bulgaria in 1978 and 1996. ${ }^{21}$ Both curves intersect once and this points to an important change in the distribution of income. For instance, in 1996 both the lowest and highest deciles increased their income share ${ }^{22}$, while intermediate deciles experienced a relative decrease. The Gini coefficient, however, did not change (26.5). In contrast, the Atkinson index with an inequality aversion parameter of one, decreased more than a point (from 11.5 to 10.4), reflecting the gain of the lowest income quintile against medium income households.

Therefore, by using both the Gini coefficient and the Atkinson indexes we can be more certain about variations in the whole income distribution. If both inequality measures move in the same direction our conclusions are more robust. If both measures behave differently this is an indication

\footnotetext{
${ }^{20}$ Dalton (1920), Kolm (1969) and Atkinson (1970).

21 The curves are estimated using the technique we describe below.

22 This can be observed by a steeper curve in these population segments.
} 
that the choice of a particular inequality index is important, since the weighting assigned to different parts of the distribution is relevant. Thus, the information given by both indexes is complementary and provides a better understanding on how income inequality is behaving.

We use four different values of $\theta(0.5,1,1.5$ and 2$)$ to obtain more information on the inequality trends. It is known that for values above one, the Atkinson index is very sensitive to abnormally low incomes (Cowell, 1995). With this in mind, we estimate the four values to have a broader picture of how $\theta$ affects the levels and trends of inequality. The most common used values of $\theta$ are 0.5 and 1 (Atkinson, et al., 1995; Burniaux, et al., 1998). In the macro literature, the conceptually equivalent risk aversion parameter is estimated to be less than one.

Figure 3: Bulgaria, Gross-household series, Lorenz curves for two different years

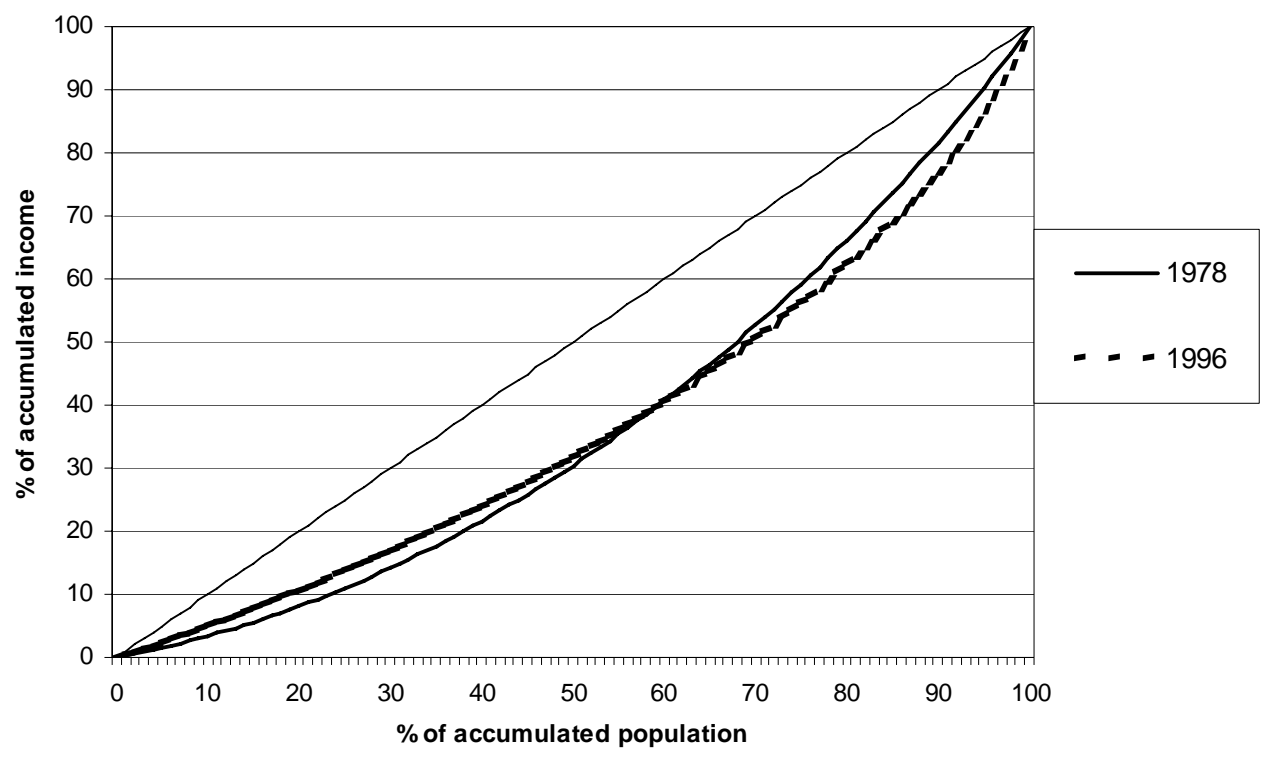

Finally, some studies do not rely entirely on indexes and use share data directly to assess inequality behavior. Indeed, one can compare the ratio of the first and fifth quintile or the extreme deciles to obtain inequality information. These ratios provide information on the gap between the richest and poorest households of the population and can be used to assess inequality dispersion.

However, this method has some important drawbacks. The most relevant is that it does not consider the distribution within income shares. The lowest quintile income share can remain unchanged, even if the poorest individuals are worst off. On the other extreme, the highest quintile share can also remain constant even when the richest individuals are much better off. Such intra- 
share changes in inequality are not measured by this kind of ratios, but are taken into account in an indicator like the Atkinson index. Moreover, there is no clear indication of which ratios are to be used and employing the extreme shares does not assure that we are comparing poor and rich individuals, since many poor people can be represented by middle shares in countries with widespread poverty. Finally, the ratios completely ignore the behavior of the middle-income households. It can be the case that the ratio of the extreme quintiles is unchanged while the middle income shares are diminishing and thus, the distribution of income is being polarized.

For the reasons listed above, we do not use such ratio measurements in this paper and instead focus on inequality indexes that provide information for the whole income distribution. To obtain information about poverty and how poor individuals are faring with respect to the rest of society, we can directly estimate the extent of poverty from the Lorenz curve. This estimation is more useful than just assuming that a particular share is representative of the poor and provides us with better information in order to assess poverty.

Additionally, it is also of practical importance to know the actual shape of the Lorenz curve, which can be directly used to asses and compare inequality. Although this information cannot be directly employed in econometric models, it provides useful information for country-specific inequality analysis and greater detail on the actual inequality experience of each country.

Finally, we could use our country results to estimate the world's Lorenz curve. However, this task has additional limitations (i.e. lack of inequality data in many countries) that require further assumptions, which exceed the scope of this paper. This estimation has already been done by Sala-iMartin (2002a, b) and we do not expect our estimations to alter the results found in these papers. ${ }^{23}$

\subsection{Parametric estimation of the Lorenz Curve from grouped data}

To construct inequality measures from grouped income data we must first obtain the Lorenz curve. There are two approaches to obtain the Lorenz curve from grouped data: simple interpolation and methods based on parameterized Lorenz curves. As explained by Datt (1998) the second method is preferred for its relative accuracy. Parametric estimation implies choosing a specific functional form and then estimating the underlying parameters. After the parameters are obtained, the Lorenz curve can be easily calculated. Nevertheless, in order to be considered as a legitimate Lorenz curve a functional form must comply with certain conditions.

${ }^{23}$ Although our country-specific Lorenz curve may be better estimated, in general the trend of reduced global inequality driven by high growth rates in China, can hardly be offset by such estimation improvements. 
If $p$ is the cumulative proportion of population and $L(p)$ is the cumulative income share of group $p, L(p)$ is a valid Lorenz curve if and only if:

$$
\begin{aligned}
& L(p) \geq 0 \quad \forall p \in(0,1) \\
& L(0)=0 \\
& L(1)=1 \\
& L^{\prime}\left(0^{+}\right) \geq 0 \quad \text { for } p \in(0,1) \\
& L^{\prime \prime}(p) \geq 0
\end{aligned}
$$

There is a large literature concerning Lorenz curve estimation and there are many proposed functional forms. Some models are better suited for specific distributions and others perform better on typical distributions. However, given that income distributions can differ widely across countries and time, no functional form is uniquely preferable. To deal with this fact, we use the most popular functional forms and for each case, we choose the one that gives the best fit. The functional forms applied at this stage, and the parameter constraints that assure a valid Lorenz curve, are discussed below.

The General Quadratic Lorenz curve. ${ }^{24}$ In this model the Lorenz curve is given by:

$$
L_{G Q}(p)=-\frac{1}{2}\left[b p+e+\left(m p^{2}+n p+e^{2}\right)^{\frac{1}{2}}\right]
$$

where $e=-(a+b+c+1) ; m=b^{2}-4 a$ and $n=2 b e-4 c$. The parameters to be estimated are then: $a, b$ and $c$. In order for (8) to represent a valid Lorenz curve we must have: $m<0, e<0, c \geq 0$ and $a+c \geq$ 1.

Pareto Family of Lorenz Curves. A group of functional forms has been derived from the wellknown classical Pareto Lorenz curve. The main difference between these models is the number of parameters employed.

\footnotetext{
24 Villaseñor and Arnold (1989).
} 
- PO: Classical Pareto. This functional form is given by:

$$
\mathrm{L}_{\mathrm{P} 0}(\mathrm{p})=1-(1-\mathrm{p})^{\pi}
$$

A valid Lorenz curve is obtained when: $0<\pi \leq 1$.

- P1: Ortega et al. (1991):

$$
L_{P 1}(p)=p^{\alpha}\left[1-(1-p)^{\pi}\right]
$$

where the necessary conditions for a valid Lorenz curve are: $0<\pi \leq 1$ and $a \geq 0$. If $a=0$ then $P 1$ reduces to $P 0$.

- P2: Rasche et al. (1980). Here we have:

$$
L_{P 2}(p)=\left[1-(1-p)^{\pi}\right]^{\beta}
$$

where the necessary conditions are: $0<\pi \leq 1$ and $\beta \geq 1$.

- P3: Sarabia et al. (1999). Combining P1 and P2 they propose:

$$
L_{P 3}(p)=p^{\alpha}\left[1-(1-p)^{\pi}\right]^{\beta}
$$

where $0<\pi \leq 1, \alpha \geq 0$ and $\beta>0$ assure a valid Lorenz curve.

Kakwani and Podder (1973) suggest the following functional form to estimate the Lorenz curve:

$$
L_{K P}(p)=p^{\alpha} \exp ^{\beta(p-1)}
$$

A valid Lorenz curve is obtained when $1<\alpha<2$ and $\beta>0$.

The Beta model. ${ }^{25}$ This Lorenz curve is given by:

$$
L_{B}(p)=p-\theta p^{\gamma}(1-p)^{\delta}
$$

25 Kakwani and Podder (1976) and Kakwani (1980). 
where $\theta, \gamma$ and $\delta$ are the parameters of the model to be estimated and we need for a valid curve that: $\theta>0,0<\gamma \leq 1$ and $0<\delta \leq 1$. However, in many cases $L_{B}(p)$ fails condition (1) even when the parameters have the right values. This is an important shortcoming of the Beta model, but we consider it here since it is one of the best performers (Datt, 1998) and the negative values it produces in the lower tail of the distribution can be easily detected.

Sarabia et al. (1999) propose a four-parameter functional form to correct for the Beta model problem. We refer to this below as the BS model:

$$
L_{B S}(p)=p^{\lambda+\gamma}\left[1-\theta(1-p)^{\delta}\right]^{\gamma}
$$

where $0 \leq \theta \leq 1, \gamma \geq 1,0<\delta \leq 1$ and $\lambda \geq 0$ assure that $L_{B S}(p)$ is a valid Lorenz curve.

\subsection{Estimation and selection of the Lorenz curve model}

In total we have seven different functional representations for estimating the Lorenz curve. Some of these can be linearized to use ordinary least square estimations, but others cannot. Therefore, we employ a non-linear estimation program using the General Algebraic Modeling System (GAMS) software package to test the seven parametric models. We also check if each model complies with the conditions to be taken as a valid Lorenz curve. When more than one model yields a valid Lorenz curve we use the standard procedure adopted in the literature and choose the model that yields a lower sum of squared residuals.

In our view, this non-linear estimation of parametric models is an improvement with respect to existing software. The POVCAL software (Chen et al., 1998) only estimates linearized models of the General Quadratic and Beta models. In some cases both models fail to provide a valid Lorenz curve and in addition, this software does not correct for Beta models that generate negative values at the bottom of the distribution. ${ }^{26}$ Furthermore, our GAMS-based program calculates the underlying income distribution associated with the estimated Lorenz curve. Using this information we are able

\footnotetext{
${ }^{26}$ Nevertheless, we use POVCAL to estimate the cumulative income shares $\mathrm{L}(\mathrm{p})$ when these are not provided directly by the source and instead, the grouped data is presented by income classes or the income data is associated with mean income and/or upper limit values.
} 
to directly estimate the Gini coefficient, the Atkinson index for the four different $\theta$ values, and poverty ratios. Nonetheless, not all the series present in the WIID database have grouped data information and thus, we have fewer estimated Gini and Atkinson indexes than the number of Gini coefficients provided by primary sources. This limits the analysis but provides additional information not present in the source Gini coefficients.

\subsection{Poverty estimation}

It is straightforward to conduct poverty headcount analysis once the entire income distribution is estimated and this procedure has the advantage of not relying on the strong assumption that the poor people are well represented by the lowest quintile or decile. To estimate poverty ratios, we use the official World Bank absolute poverty lines of one and two dollars a day (Ravallion et al., 1991). The income levels are taken from the PPP-adjusted GDP values of the Penn World Tables version $6.1 .^{27}$

However, the use of GDP data as an income indicator is problematic. First, inequality data is drawn from household surveys and there is a substantial discrepancy between the national income reported from these household surveys and that from national accounts data. The difference is mainly explained because GDP not only includes private consumption, but also private investment and government spending. Secondly, the poverty lines were calculated using mean consumption levels in poor countries and therefore, include only the most basic consumption needs and they do not take into account public services or investment.

Following these considerations, there are two main approaches to estimate absolute poverty. The World Bank (Chen and Ravallion 2001, 2004) uses consumption and inequality data both drawn from household surveys. On the other hand, we follow Sala-i-Martin (2002a, b) and estimate poverty rates using inequality data from household surveys, but per capita income from national accounts data. This later approach allows us a larger series. In addition, it indirectly accounts for governmental expenditure and other non-private consumption sources of goods and services for the poor.

The two methods can yield significantly different poverty estimates for a given poverty line. Yet, in recent articles (Chen and Ravallion, 2004; and Ravallion, 2004) it is shown that both methods produce very similar results when the World Bank method uses the $\$ 1 /$ day poverty line and the other method uses $\$ 2 /$ day. Moreover, Ravallion (2001) finds that, with the exception of the

${ }^{27}$ The poverty lines were reported in 1985 values and the PWT data is in 1996 dollars. Thus, the equivalent annual income of $\$ 1 /$ day is $\$ 532$ and for $\$ 2 /$ day is $\$ 1064$ (Sala-i-Martin, 2002a, b). 
transition economies of Eastern Europe and the Former Soviet Union, growth rates of national accounts measures are not systematically different from growth rates of household survey measures. To sum up, using a $\$ 2 /$ day poverty line we obtain poverty estimates roughly equivalent to the $\$ 1 /$ day absolute poverty based on consumption and we expect that this equivalence does not change over time.

Formally, the headcount poverty ratio is defined as the number of individuals with an income below the poverty line in relation to the total population:

$$
P R_{z}=\frac{\int_{0}^{z} I(y) d y}{\int_{0}^{\infty} I(y) d y}
$$

where $z$ is the poverty line and $I(y)$ is the distribution function of income $y$.

We estimate the poverty ratio using a GAMS program similar to the one used in our previous section. Nonetheless, since we are now primarily interested in the lower tail of the income distribution, we select the model that provides a valid Lorenz curve that fits best the lower quintile of the distribution. Moreover, we use a discrete version of the previous formula. For instance, we divide the population in a thousand $q$ units and estimate the income of each unit using the formula: ${ }^{28}$

$$
I(q)=G D P_{p c} * I S(q) * 1000
$$

where $G D P_{p c}$ is gross domestic product per capita, $I S(q)$ is the income share of unit $q$. The poverty ratios are given by the sum of the number of units with an income below the two poverty lines ( $\$ 1 /$ day and $\$ 2 /$ day), divided by the total population. The total number of poor can easily be obtained by multiplying the poverty ratio by the total population. With a similar procedure, it is also straightforward to estimate other poverty indexes, such as the poverty gap and the Foster-GreerThorbecke index.

${ }^{28}$ The formulas to integrate the poverty ratios are complicated by the non-linearity of most of the Lorenz curve models. However, with a thousand units we have a three digit approximation of the real value. 


\section{Evaluating the data}

On the basis of the previous two sections we have constructed a new inequality dataset. Unlike the DS series, we have several inequality series for each country (gross-household, net-household and expenditure-person), five inequality measures (Gini coefficient and four Atkinson indexes) and two types of series based on their reliability (basic and extended). ${ }^{29}$ To assess the implementation of our comparability assumptions, we begin by comparing our dataset with that of DS. We also check how our estimated Gini coefficients fare with respect to the source information provided in the WIID. Finally, we examine whether the Gini coefficient and the Atkinson index yield similar results.

\subsection{Differences between our series and DS}

In general, we want to know if inequality levels and time trends are significantly different when moving from one dataset to the other. Inequality levels are important for cross-country comparisons, while time trends provide information on specific country inequality behavior and are relevant when analyzing pooled data.

A first comparison shows that for the 427 observations of the basic gross income-household series (which is the most similar series to that of DS), there is a coincidence in country and year for 348 observations with respect to the DS-accept series. This represents an $81.5 \%$ of the total number of observations for the basic series. Moreover, the correlation between both series is fairly high at 0.97. In the case of the extended gross income-household series the percentage of coincidence is of $70 \%$ and the correlation is also of 0.97 . Therefore, even when our series and the DS-accept series are highly correlated and share many observations for the same year and country, there is also an important percentage of observations not included or shared by both series. These dissimilarities can produce significant divergences in the level and trend information provided by both inequality datasets.

\subsection{Level differences}

$\mathrm{AB}$ find serious level differences when comparing the DS dataset with the LIS information. Since the LIS was conducted explicitly to render OECD inequality data comparable, it is a reliable indicator on which to compare the inequality levels for OECD countries. Thus, we follow AB and

${ }^{29}$ The summary statistics for the Atkinson indexes and our own Gini estimates are given in Table 5, under the column: share data. 
compare our dataset with the LIS information for a single year (1991 or the closest available). The results are shown in Table 7.

Table 7: OECD country rankings, Gini Gross-household series for one year

\begin{tabular}{|c|c|c|c|c|c|c|}
\hline \multirow[b]{2}{*}{1} & \multicolumn{2}{|l|}{ LIS } & \multicolumn{2}{|c|}{ Basic series } & \multicolumn{2}{|c|}{ DS-accept } \\
\hline & $\overline{\text { Finland }}$ & 29.61 & $\overline{\text { Finland }}$ & 29.61 & $\overline{\text { Finland }}$ & 26.11 \\
\hline 2 & Netherlands & 30.59 & Netherlands & 30.59 & Belgium & 26.92 \\
\hline 3 & Sweden (1992) & 31.11 & Sweden & 31.11 & Canada & 27.65 \\
\hline 4 & Germany (1983) & 31.37 & Germany & 31.37 & Great Britain & 27.80 \\
\hline 5 & Norway & 31.81 & Norway & 31.81 & Netherlands & 29.38 \\
\hline 6 & Belgium (1992) & 31.95 & Belgium & 31.95 & Germany & 31.37 \\
\hline 7 & Denmark (1992) & 33.20 & Denmark & 33.20 & Sweden & 32.44 \\
\hline 8 & France (1984) & 34.91 & France & 34.91 & Denmark & 33.20 \\
\hline 9 & Canada & 35.08 & Canada & 35.08 & Norway & 33.31 \\
\hline 10 & Great Britain (1986) & 36.18 & Great Britain & 36.18 & France & 34.91 \\
\hline 11 & USA & 39.15 & USA & 39.15 & USA & 37.94 \\
\hline
\end{tabular}

Note: In the LIS ranking we state the year of the inequality observation when it is not 1991.

For this specific year our observations are exactly the same as the LIS and thus we have the same country ranking. However, the ranking provided by the DS series is very different. This is evident in the low inequality reported for Canada and Great Britain, and the higher inequality in Sweden and Norway. The results are similar when evaluating net income rankings. In Table 8 our basic series is almost identical to that of LIS, the only difference being the observation for Italy, which is very low in the LIS series. On the other hand, the DS accept series once more provides a completely different ranking. For example, Spain has a very low inequality since DS use expenditure information for this country. Once more, Great Britain and Canada have surprisingly low positions and Sweden and Norway very high ones.

One can argue that a one-year ranking check is not adequate, since a single uncharacteristic observation can alter the results. Thus, we also rank the OECD countries by average Gini coefficients for a five year period: 1983-1987. We choose this period since it provides the most LIS observations possible. The results for the gross-household series are given in Table 9 and those for net-household in Table 10. 
Table 8: OECD country rankings, Gini Net-household series for one year

\begin{tabular}{|c|c|c|c|c|c|c|}
\hline \multirow[b]{2}{*}{1} & \multicolumn{2}{|l|}{ LIS } & \multicolumn{2}{|c|}{ Basic series } & \multicolumn{2}{|c|}{ DS-accept } \\
\hline & Finland & 26.11 & Finland & 26.11 & $\overline{\text { Spain }}$ & 25.91 \\
\hline 2 & Belgium (1992) & 26.92 & Belgium & 26.92 & Finland & 26.11 \\
\hline 3 & Italy & 27.12 & Norway & 28.80 & Belgium & 26.92 \\
\hline 4 & Norway & 28.80 & Sweden & 29.16 & Canada & 27.65 \\
\hline 5 & Sweden (1992) & 29.16 & Germany & 29.36 & Great Britain & 27.80 \\
\hline 6 & Germany (1983) & 29.36 & Netherlands & 29.38 & Netherlands & 29.38 \\
\hline 7 & Netherlands & 29.38 & Denmark & 29.96 & Germany & 31.37 \\
\hline 8 & Denmark (1992) & 29.96 & Spain & 30.60 & Italy & 32.19 \\
\hline 9 & Spain (1990) & 30.60 & Canada & 31.47 & Sweden & 32.44 \\
\hline 10 & Canada & 31.47 & France & 31.94 & Denmark & 33.20 \\
\hline 11 & France (1984) & 31.94 & Italy & 32.19 & Norway & 33.31 \\
\hline 12 & Australia (1989) & 32.85 & Australia & 32.85 & France & 34.91 \\
\hline 13 & Great Britain (1986) & 33.29 & Great Britain & 33.29 & Australia & 37.32 \\
\hline 14 & USA & 35.24 & USA & 35.24 & USA & 37.94 \\
\hline
\end{tabular}

Note: For Spain the LIS observation refers to family equivalent from an extended series.

In the LIS ranking we state the year if it is not 1991.

Again our basic series for gross income ranks the OECD in a very similar way as the LIS. Nevertheless, the DS series once more yields an unsuitable ranking. Great Britain is again very highly positioned and Norway too low. When turning to net income, some differences appear between our data and the LIS with respect to Finland, Great Britain and Australia. The difference is justified in these cases by the existence of more observations in our basic series than those in the LIS dataset.

We can draw two conclusions from this example of OECD countries. First, our series are compatible with the LIS and the few divergences are justified by more observations present in our series. The second conclusion is that the DS accept series yields some rankings that are very hard to justify and can only be explained by the inconsistent use of different income concepts. 
Table 9: OECD country rankings, Gini Gross-household series, average for 1983-1987

\begin{tabular}{|c|c|c|c|c|c|c|}
\hline & \multicolumn{2}{|c|}{ LIS } & \multicolumn{2}{|c|}{ Basic series } & \multicolumn{2}{|c|}{ DS-accept } \\
\hline 1 & $\overline{\text { Belgium }}$ & 26.22 & Belgium & 26.22 & Belgium & 26.22 \\
\hline 2 & Finland & 30.10 & Norway & 29.44 & Great Britain & 27.14 \\
\hline 3 & Norway & 30.36 & Finland & 30.30 & Netherlands & 28.94 \\
\hline 4 & Sweden & 30.77 & Sweden & 30.77 & Finland & 29.34 \\
\hline 5 & Germany & 31.78 & Netherlands & 31.69 & Sweden & 31.30 \\
\hline 6 & Netherlands & 32.94 & Germany & 31.78 & Norway & 31.69 \\
\hline 7 & Denmark & 33.15 & Denmark & 33.15 & Germany & 31.78 \\
\hline 8 & Canada & 34.28 & Canada & 34.67 & Canada & 32.67 \\
\hline 9 & France & 34.91 & France & 34.91 & Denmark & 33.15 \\
\hline 10 & New Zealand & 35.00 & New Zealand & 35.48 & France & 34.91 \\
\hline 11 & Great Britain & 36.18 & Great Britain & 36.18 & New Zealand & 35.48 \\
\hline 12 & Australia & 36.50 & USA & 38.93 & USA & 37.20 \\
\hline 13 & USA & 39.23 & Australia & 39.09 & Australia & 39.09 \\
\hline
\end{tabular}

Note: The New Zealand LIS observation refers to family.

We only have an extended series for Finland.

Table 10: OECD country rankings, Gini Net-household series, average for 1983-1987

\begin{tabular}{|c|c|c|c|c|c|c|}
\hline \multirow[b]{2}{*}{1} & \multicolumn{2}{|c|}{ LIS } & \multicolumn{2}{|c|}{ Basic series } & \multicolumn{2}{|c|}{ DS-accept } \\
\hline & Finland & 26.19 & Belgium & 26.22 & Belgium & 26.22 \\
\hline 2 & Belgium & 26.22 & Norway & 26.87 & Great Britain & 27.14 \\
\hline 3 & Netherlands & 28.35 & Sweden & 28.64 & Netherlands & 28.94 \\
\hline 4 & Norway & 28.35 & Netherlands & 28.94 & Finland & 29.34 \\
\hline 5 & Sweden & 28.64 & Finland & 29.34 & Sweden & 31.30 \\
\hline 6 & Germany & 29.36 & Germany & 29.36 & Norway & 31.69 \\
\hline 7 & Canada & 31.21 & Canada & 29.87 & Germany & 31.78 \\
\hline 8 & Denmark & 31.30 & Denmark & 31.30 & Canada & 32.67 \\
\hline 9 & Australia & 31.49 & Great Britain & 31.84 & Denmark & 33.15 \\
\hline 10 & France & 31.94 & France & 31.94 & Italy & 33.80 \\
\hline 11 & Italy & 32.78 & Italy & 33.80 & France & 34.91 \\
\hline 12 & Great Britain & 33.29 & USA & 34.93 & USA & 37.20 \\
\hline 13 & USA & 35.24 & Australia & 36.24 & Australia & 39.09 \\
\hline
\end{tabular}

In the case of developing countries, there is no equivalent to the LIS that we can use as a benchmark to compare datasets. However, the differences in levels between our basic series and the DS accept series persist. When ranking OECD countries some differences were produced by the loose interchange of net and gross income data present in the DS series. For developing countries the source of divergence in levels is produced by mixing expenditure and gross income data. Since 
expenditure data is significantly lower than gross income data, this alters the inequality levels between countries.

The use of fixed adjustments can help to render the DS series comparable to the LIS. If provisions are made to adjust for income differences some of the divergences shown before disappear. However, there is still an element of arbitrariness in the procedure. How much should we adjust the series? The countries average difference or the overall average? The decision of which fixed adjustment to apply affects the outcome and the resulting country rankings. Thus, the previous results support the idea that mixing different income concepts can lead to misguiding conclusions and is an important limitation for inequality cross-country studies.

\subsection{Time trend differences}

While the inclusion of fixed adjustments to the series addresses level-differences, it does not help with time trends. In particular, when the time trend of series with different definitions is not the same, mixing the series creates a whole new trend. In many cases, the use of a fixed adjustment does not correct for this problem. Therefore, we proceed to compare the time-trend differences between our basic and extended series, with the DS accept series. To do so, we regress the Gini coefficient against time for those series that have five or more observations. We use two equations: ${ }^{30}$

$$
\begin{aligned}
& G_{i}=\alpha_{1}+\alpha_{2} t_{i}+\varepsilon_{i} \\
& G_{i}=\beta_{1}+\beta_{2} t_{i}+\beta_{3} t_{i}^{2}+\varepsilon_{i}
\end{aligned}
$$

The first regression tests for any linear time trends and the second for quadratic trends. To do a valid comparison of our series with the DS-accept series we do not take into consideration information that was not available to DS (data after 1996 and studies published after this year). We limit the analysis to the three main series: gross-household, net-household and expenditure-person. In total we study 44 basic series, 29 extended series and 43 DS-accept series with five or more observations, where $45 \%$ of the series come from OECD countries. To have a statistically significant trend, we must find that $\alpha_{2}$ is significantly different from zero and/or that $\beta_{2}$ and $\beta_{3}$ are jointly different from zero. In total, $25 \%$ of the basic series have a different time trend than the DSaccept series. The figure is over $66 \%$ in the case of the extended series.

\footnotetext{
${ }^{30}$ Given the small number of observation per country, we do not pursue a time series analysis.
} 
We can also analyze only those series with ten or more observations. Although the number of series decreases, the results remain the same. In this case we have 30 basic, 15 extended series and 20 DS-accept series. We find that $23 \%$ of the basic series and $73 \%$ of the extended series have a different time trend than the DS-accept series. The OECD proportion of observations remains close to half (47\%). These comparisons show significant time trend differences between both datasets, which suggests dissimilar conclusions regarding inequality variation.

As an example we present the case of Sweden. There are two main sources: LIS and SAS for both the net and gross-household series. However, when conducting our comparability analysis both sources are rendered not comparable and thus, we do not mix them. Instead, we choose the LIS series, which has fewer observations than the SAS series, but has a larger time span and provides better cross-country comparisons, as explained earlier. In Figure 4 we plot our two basic series and the DS-accept series. The first two DS observations are taken from the LIS series but the remaining are from the SAS series.

\section{Figure 4: Sweden, Gini coefficient, basic series and DS-accept series}

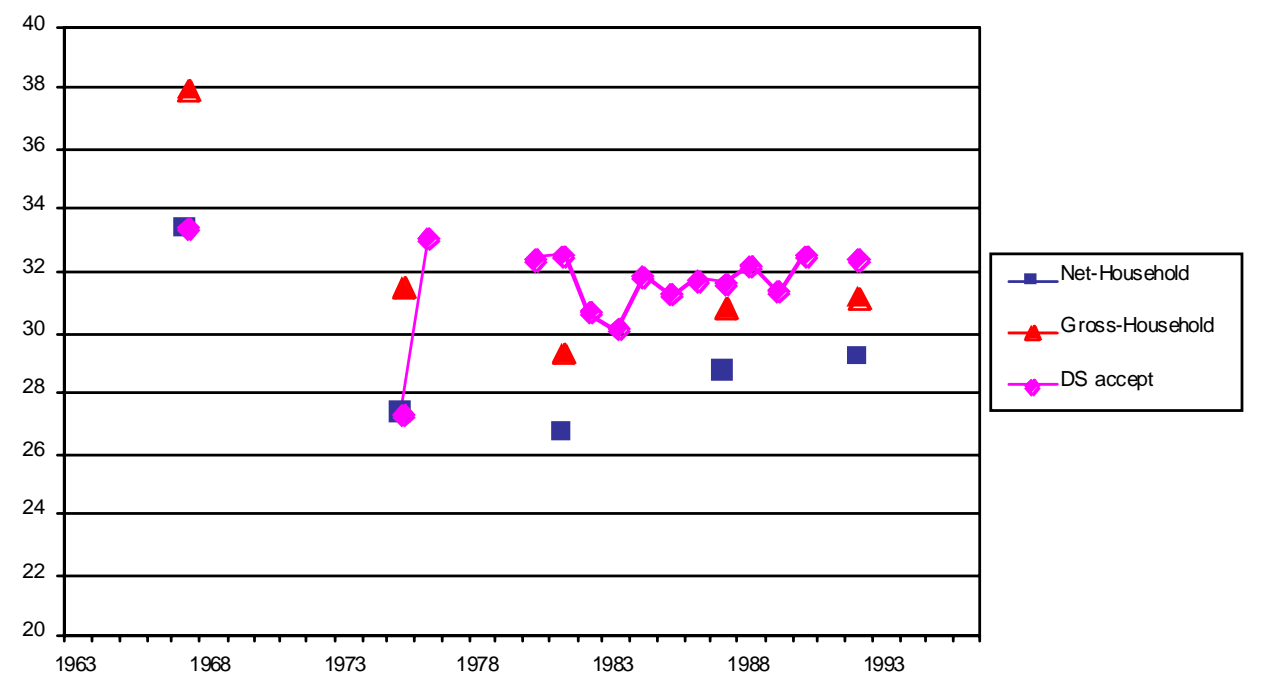

The first conclusion is that the levels are different. This was already analyzed in the previous section. More interesting, the DS-accept series fails to show any time trend at all. ${ }^{31}$ From our basic

31 This could be corrected by a fixed adjustment of the net income series. However, DS do not find any significant difference between net and gross income, and thus, do not apply any adjustment in this case. 
series it is clear that there is a trend, in particular a U-shape pattern. This also is corroborated by significant coefficients in the quadratic regression.

Another compelling example is Canada. In Figure 5 we present two of our basic series and the DS-accept series. The gross-household series has been adjusted by the LIS data and thus, has a different level from the DS-accept series until the 1988 observation. After this year the series diverge, DS take some observations which fail the WIID quality criteria. Instead, we use the LIS observation for 1991. Although the last part of the two series show different time trends, there is no overall time trend in both series. However, when using our basic net-household series, we have significant coefficients for the quadratic form regression, i.e., we spot again the U-shape pattern. This is a clear example of the limitations of using a single inequality series per country. Moreover, the dummy variable solution does not work here, since a fixed adjustment does not solve the inconsistency and the time trend does not change.

Figure 5: Canada, Gini coefficient, basic series and DS-accept series

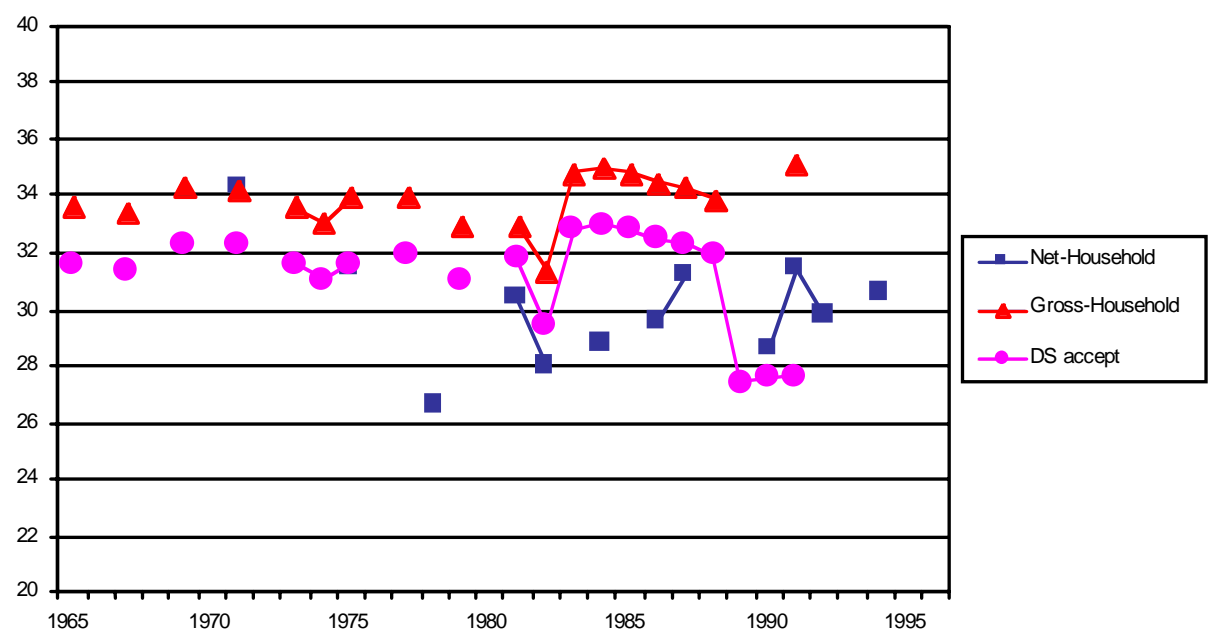

There are many other cases in the data that show different levels and time trends between our series and the DS-accept. Most of the differences are given by the grouping approach used; not only by the income concepts and reference units, but also by incompatible sources. On the other hand, there are some differences that are provided by the quality labels used. In the example of Canada we rejected 
some observations used in DS. Sometimes it is the other way around and we include observations not labeled as high quality by DS, but accepted as reliable data by the WIID. ${ }^{32}$

Overall, the differences are significant and it is clear that the decision regarding how to group different definitions is essential when analyzing inequality data. Furthermore, the use of dummy variables or fixed adjustments does not solve the problem satisfactorily. (In a recent paper, Deininger and Squire 2002 continue to recommend this practice.) Again, we agree with AB and conclude that researchers employing inequality data should be careful when using the DS-accept series. On the other hand, our dataset does comply with the recommendations of AB:

"A secondary dataset should be a consolidation of earlier work, with multiple observations for the same country and the same date being justified by differences in source, in definition, or in methods of calculation."

\subsection{Compatibility of the source and our estimated Gini coefficients}

We turn our attention to our own estimated Lorenz curves. It is a straightforward exercise to obtain Gini coefficients and Atkinson indexes once the Lorenz curve is estimated. ${ }^{33} \mathrm{With}$ this information we first test how our estimated Gini coefficients compare to the source information. Afterwards, we analyze if the Atkinson indexes do effectively convey different or additional information on inequality than the Gini coefficient alone.

In order to compare our Gini estimates and the source coefficients we conduct the same comparability tests done above. Again we limit our analysis to the three main series: gross-household, net-household and expenditure-person. We obtain 87 comparable series, of which 85\% are fully comparable with an average difference $(c)$ of zero; $92 \%$ are fully comparable with $c \leq|1|$ and $95 \%$ with $c \leq|2|$. The average difference between series is of -0.15 and the average difference weighted by the number of observations is -0.17 . These results show a very good estimation of the Gini coefficients from our constructed Lorenz curves.

\footnotetext{
32 A noteworthy example is the data presented by Paukert (1973). Most of his data is not accepted by DS because it lacks a clear reference to the primary source. However, the WIID accepts all his observations. Since this source provides information from the 1960s it expands many country series and thus, may alter the time trends for some countries. For instance, Barro (2000) also uses observations that do not pass this "primary source" quality test.

${ }^{33}$ Using the chosen parametric equation we can construct the whole income distribution and the Lorenz curve. In our case, we use centuples to do so. The resulting inequality indexes do not change significantly if a lower unit is used.
} 
Moreover, of the three non-comparable estimations, two of them can be explained by inconsistent source information for one particular year. For example, the expenditure-person series of Estonia has a Gini estimate of 39.47 for 1993 while the source value is of 31.52 (see Table 11). This single observation renders the series incompatible.

Table 11: Estonia, Expenditure-Person series, share data and Gini coefficients

\begin{tabular}{ccc|cccc}
\hline Year & Gini (source) & Gini est. & Quintile 1 & Quintile 2 & Quintile 3 & Quintile 4 \\
& & & & & & \\
1992 & 35.82 & 35.79 & 0.0702 & 0.1879 & 0.3490 & 0.5691 \\
1993 & 31.52 & 39.47 & 0.0624 & 0.1717 & 0.3245 & 0.5386 \\
1995 & 36.63 & 36.60 & 0.0691 & 0.1835 & 0.3423 & 0.5623 \\
\hline
\end{tabular}

Source: WIID and DS datasets

Yet, a closer inspection of the accumulated share data reveals a source inconsistency. All the quintile accumulated income shares are higher for 1992 and 1995, but the Gini coefficients are higher in both years. This result is very contradictory and can be a typo in the source data. ${ }^{34}$ On the other hand, our Gini estimate is consistent with the share information.

In general, our estimates are very close to the source information and we can be assured of the quality of our estimated Gini coefficients. This also provides confidence in the values of the Atkinson indexes that also use the constructed Lorenz curves. Li et al. (1998) state that the estimation methods vary across different sources and therefore, the use of one standard technique can minimize this problem. Consequently, our main series include our own estimations when there is income share information, and the source data when there is no way to estimate the Gini coefficient and the Atkinson indexes. This procedure introduces a distinctive characteristic to our inequality dataset. ${ }^{35}$

${ }^{34}$ From equations (4) and (5) we know that the Lorenz curve for 1992 and 1995 dominates that of 1993 for the whole middle section of the distribution. Thus, the lower Gini value given by the source could only be justified by significant differences at the extremes of the distribution in 1993. However, given that the Gini attaches more weight to the middle of the distribution this possibility seems very unlikely.

${ }^{35}$ Nevertheless, we retain both source for the Gini coefficient and this allows us to test the robustness of our results. 


\subsection{Comparing Gini- Atkinson-based indexes}

We turn to the inequality results provided by the two measures we have. First, we check the behavior of the Atkinson index for each value of $\theta$. Afterwards we compare the Atkinson and the Gini data. Throughout the section, we only use our estimated Gini coefficients. In this way we have the same sample as the Atkinson index and both indexes are derived from the same estimation technique.

\section{$\underline{\text { Atkinson index results }}$}

As expected, the level and variance of the Atkinson index increases with $\theta$. The higher the inequality aversion, the index gives higher values and also is more sensitive to changes in the distribution (see Table 12). The overall values of the net income series are lower than those of the expenditure series because the first series has more OECD countries in its sample and the later more developing countries. In fact, from the Gini coefficient values we know that the level of inequality and the variance between OECD countries is smaller than for developing countries.

\section{Table 12: Basic series statistics for different indexes}

\begin{tabular}{|c|c|c|c|c|c|c|}
\hline & \multicolumn{2}{|c|}{ Gross-household } & \multicolumn{2}{|c|}{ Net-household } & \multicolumn{2}{|c|}{ Expenditure-person } \\
\hline & Mean & Variance & Mean & Variance & Mean & Variance \\
\hline Atkinson $\theta=0.5$ & 14.27 & 6.92 & 8.59 & 2.64 & 12.72 & 10.82 \\
\hline Atkinson $\theta=1$ & 25.96 & 17.31 & 16.9 & 8.00 & 22.63 & 29.66 \\
\hline Atkinson $\theta=1.5$ & 36.9 & 35.57 & 25.53 & 22.68 & 30.64 & 50.23 \\
\hline Atkinson $\theta=2$ & 46.63 & 65.71 & 34.91 & 69.50 & 37.27 & 69.23 \\
\hline Gini coefficient & 39.9 & 10.39 & 31.38 & 5.81 & 38.53 & 18.96 \\
\hline
\end{tabular}

\section{Differences between the Atkinson and the Gini}

In the following sections we analyze only the two middle Atkinson indexes. Furthermore, we only consider series with five or more observations. First we explore how the two inequality indexes rank a sample of countries and then we analyze the time-trend information that both indexes provide. 
Level differences. In Table 13 we rank a sample of 13 countries by the three inequality indexes. We use the average for the whole 1980s decade. In general, the Atkinson ranking is very similar to that given by the Gini coefficient. The only significant difference is in the ranking of Canada and Bangladesh for the last index. Thus, although the Atkinson provides lower levels, this does not change much the relative position of each country.

Table 13: Rankings based on basic gross-household series, 1980s average

\begin{tabular}{|c|c|c|c|c|c|c|}
\hline \multirow[b]{2}{*}{1} & \multicolumn{2}{|c|}{ Gini coefficient } & \multicolumn{2}{|c|}{ Atkinson $\theta=1$} & \multicolumn{2}{|c|}{ Atkinson $\theta=1.5$} \\
\hline & Bulgaria & 22.66 & Bulgaria & 8.79 & Bulgaria & 12.59 \\
\hline 2 & Germany & 31.38 & Germany & 16.78 & Germany & 25.62 \\
\hline 3 & Canada & 33.94 & Spain & 18.84 & Spain & 27.57 \\
\hline 4 & Spain & 34.27 & Canada & 19.40 & Bangladesh & 29.09 \\
\hline 5 & Japan & 34.49 & Japan & 19.61 & Japan & 29.28 \\
\hline 6 & Korea & 36.19 & Korea & 21.20 & Korea & 30.13 \\
\hline 7 & Bangladesh & 37.52 & Bangladesh & 21.71 & Canada & 32.79 \\
\hline 8 & Australia & 38.40 & Australia & 23.75 & Australia & 34.64 \\
\hline 9 & United States & 38.45 & United States & 25.76 & Hong Kong & 36.17 \\
\hline 10 & Hong Kong & 42.40 & Hong Kong & 26.71 & United States & 40.19 \\
\hline 11 & Bahamas & 43.15 & Bahamas & 32.89 & Colombia & 50.48 \\
\hline 12 & Colombia & 51.16 & Colombia & 37.89 & Bahamas & 50.81 \\
\hline 13 & Brazil & 56.98 & Brazil & 45.45 & Brazil & 57.96 \\
\hline
\end{tabular}

However, the Atkinson index provides additional information about income distribution. In Table 14 we rank the 12 countries that have a basic net-household series with more than five observations. The general ranking does not change much from index to index, but it does have some interesting cases. For example, Sweden has a relatively high inequality for the Atkinson indexes and Italy a relatively low one. A closer inspection of the share information shows that the difference is provided by the lowest quintile, where Italy has an average share income of $8.2 \%$ and Sweden of $7.4 \%$. Therefore, Italy has a lower Atkinson level when $\theta=1.5$. Yet, the middle quintiles are very similar and Sweden's highest quintile has around four points less. This explains the lower inequality when $\theta$ $=1$ or when we use the Gini coefficient. 
Table 14: Rankings based on basic net-household series, 1980s average

\begin{tabular}{|c|c|c|c|c|c|c|}
\hline \multirow[b]{2}{*}{1} & \multicolumn{2}{|c|}{ Gini coefficient } & \multicolumn{2}{|c|}{ Atkinson $\theta=1$} & \multicolumn{2}{|c|}{$\begin{array}{c}\text { Atkinson } \theta=1.5 \\
\end{array}$} \\
\hline & Romania & 23.37 & Romania & 9.04 & Romania & 13.74 \\
\hline 2 & Poland & 25.06 & Norway & 9.74 & Poland & 14.29 \\
\hline 3 & Norway & 26.84 & Poland & 9.87 & Norway & 17.20 \\
\hline 4 & Sweden & 27.44 & Netherlands & 12.50 & Netherlands & 18.89 \\
\hline 5 & Netherlands & 27.44 & Germany & 13.26 & Germany & 19.86 \\
\hline 6 & Germany & 28.58 & Sweden & 13.67 & Italy & 20.29 \\
\hline 7 & Taiwan & 29.09 & Taiwan & 13.82 & Taiwan & 21.05 \\
\hline 8 & Italy & 30.18 & Italy & 14.11 & Sweden & 21.93 \\
\hline 9 & Finland & 30.94 & Finland & 16.88 & Finland & 25.24 \\
\hline 10 & Great Britain & 33.76 & Great Britain & 17.01 & Great Britain & 25.39 \\
\hline 11 & United States & 34.43 & United States & 21.67 & United States & 34.08 \\
\hline 12 & Mexico & 46.45 & Mexico & 31.42 & Mexico & 41.79 \\
\hline
\end{tabular}

Time trend differences. To analyze the time trend information provided by both inequality measures, again we only use the three main series for those countries with five or more observations, and we regress once more equations (16) and (17). We have a sample of 60 sets of observations, 23 of those representing OECD countries. For $\theta=1$ the Atkinson index yields a different time trend in $27 \%$ of the cases from that of the Gini coefficient. When $\theta=1.5$ the difference increases to $31 \%$. If we expand the series length to ten or more observations the results are similar: $31 \%$ for $\theta=1$ and $28 \%$ for $\theta=1.5$. Therefore, we can conclude that the Atkinson index gives a different time trend in roughly a third of all cases. This is a significant divergence and confirms that the changes in different parts of the income distribution can be responsible for both indexes reporting different inequality results.

In summary, although there is not much variation in the ranking given by both inequality indexes, there are important differences when we analyze the time trend information. The Atkinson index does convey additional information about the extremes of the distribution and as such is, in our view, a useful resource when analyzing inequality data.

\section{International and intertemporal patterns of inequality}

As before, in this section we use our three main series and in addition, we use our own Gini estimates when share data are available. First we summarize the characteristics of the basic and extended series and we end the section by analyzing how inequality varies across and within countries. 


\subsection{Descriptive information}

In the Appendix we present the summary statistics for our six series: three basic and three extended. It is important to remember that the net income series are more representative of OECD countries, the expenditure series of developing countries and the gross income series have a balanced sampled between both groups. The disparities in the sampled countries of each series make it difficult to compare the results when different income concepts are used. Nonetheless, a simple examination of the tables shows that the gross income series have a higher mean and standard deviation on average. The standard deviation is very similar for the net income and expenditure series, while the last have a higher mean on average.

We also present for each series the results of a simple ANOVA analysis, which shows the percentage of variation represented by between and within country changes. The results are homogeneous and for each series between-country variation represents between $80 \%$ and $90 \%$ of total variation. This suggests that inequality levels are more important than inequality trends, a conclusion also reached by Li, et al. (1998). However, in our case the within-country variation is also significant and thus, we find evidence for the weaker hypothesis they test, i.e., that inter-temporal shifts in inequality are modest compared with international differences.

\subsection{International patterns}

Using again the two time trend equations, we run random-effect regressions on the six series. Here we want to find if there are any inequality patterns that are common to countries and groups. The results are presented in Table 15.

Table 15: Random-effect regressions of Gini series

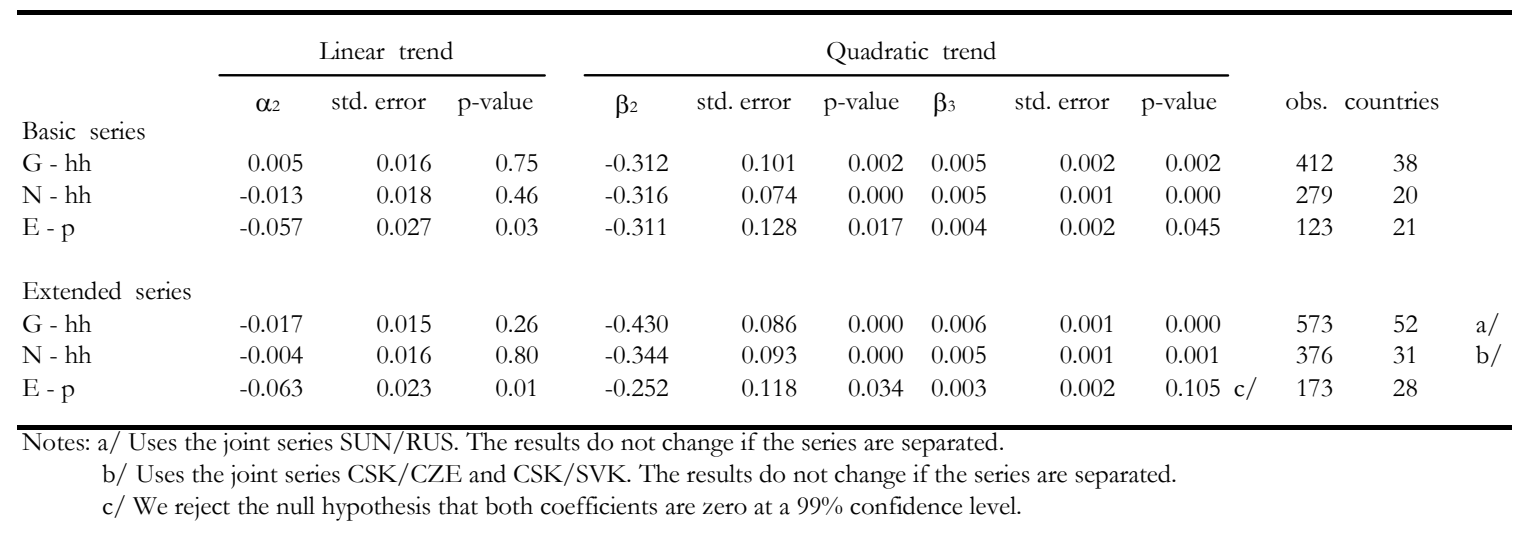


First there is no linear pattern in the gross and net income series. The expenditure series has a significantly decreasing trend. However, all six series do present significant quadratic trends. In particular, all the series reveal a U-shape pattern with a significantly negative $\beta_{2}$ and a positive $\beta_{3}$. These results support the idea of what Atkinson (2003) labeled the "U-turn" pattern. This is represented by a decrease of inequality after the Second World War and a turning point around the 1980s when inequality began to increase again. ${ }^{36}$ In particular, for the gross and net series the turning point is around the late 1970s and early 1980s. Although Atkinson finds this pattern for OECD countries, our results suggest that it may represent a broader phenomenon. ${ }^{37}$

Additionally, the values of the quadratic coefficients produce a different U-pattern for the extended expenditure series. It has a prominent decrease in inequality and the turning point is in the mid-1990s. These divergent results suggest that the sample of countries may be behaving differently, since expenditure series represent mainly developing countries. Therefore, to analyze this point further we divide the series by OECD and developing countries (non-OECD). The results are shown in Table 16.

Table 16: Random effects regressions: Gini, OECD and developing countries separated

\begin{tabular}{|c|c|c|c|c|c|c|c|c|c|c|c|c|c|}
\hline \multirow[b]{3}{*}{ Non-OECD sample } & \multicolumn{3}{|c|}{ Linear trend } & \multicolumn{7}{|c|}{ Quadratic trend } & \multirow[b]{2}{*}{ obs. } & \multirow{2}{*}{\multicolumn{2}{|c|}{ countries }} \\
\hline & $\alpha_{2}$ & std. error & $\mathrm{p}$-value & $\beta_{2}$ & std. error & $\mathrm{p}$-value & $\beta_{3}$ & std. error & p-value & & & & \\
\hline & & & & & & & & & & & & & \\
\hline G-hh basic & -0.022 & 0.027 & 0.40 & -1.012 & 0.536 & 0.060 & 0.015 & 0.008 & 0.050 & a/ & 224 & 22 & \\
\hline E-p basic & -0.056 & 0.027 & 0.04 & -0.316 & 0.130 & 0.016 & 0.004 & 0.002 & 0.043 & & 120 & 20 & \\
\hline G-hh extended & -0.025 & 0.023 & 0.26 & -1.358 & 0.541 & 0.013 & 0.018 & 0.008 & 0.021 & & 340 & 35 & $\mathrm{~b} /$ \\
\hline E-p extended & -0.061 & 0.024 & 0.01 & -0.219 & 0.144 & 0.132 & 0.002 & 0.002 & 0.231 & a/ & 151 & 24 & \\
\hline OECD sample & & & & & & & & & & & & & \\
\hline $\begin{array}{l}\text { G-hh basic } \\
\text { E-p basic }\end{array}$ & $\begin{array}{l}0.030 \\
0.014\end{array}$ & $\begin{array}{l}0.018 \\
0.018\end{array}$ & $\begin{array}{l}0.10 \\
0.43\end{array}$ & $\begin{array}{l}-0.265 \\
-0.267\end{array}$ & $\begin{array}{l}0.074 \\
0.074\end{array}$ & $\begin{array}{l}0.000 \\
0.000\end{array}$ & $\begin{array}{l}0.005 \\
0.005\end{array}$ & $\begin{array}{l}0.001 \\
0.001\end{array}$ & $\begin{array}{l}0.000 \\
0.000\end{array}$ & & $\begin{array}{l}188 \\
200\end{array}$ & $\begin{array}{l}16 \\
15\end{array}$ & \\
\hline G-hh extended & -0.008 & 0.019 & 0.69 & -0.256 & 0.083 & 0.002 & 0.004 & 0.001 & 0.002 & & 233 & 17 & \\
\hline E-p extended & 0.015 & 0.018 & 0.41 & -0.261 & 0.071 & 0.000 & 0.004 & 0.001 & 0.000 & & 220 & 18 & \\
\hline
\end{tabular}

For the case of OECD countries the results are very robust. For the four analyzed series there is no linear trend but a quadratic U-pattern. On the other hand, the series for developing countries present different results. The gross-household basic series do not have any significant trend, while the extended series presents the familiar U-pattern. Moreover, both expenditure series have

\footnotetext{
${ }^{36} \mathrm{Li}$, et al. (1998) fail to find any significant time trend. However, they only use the linear approach.

${ }^{37} \mathrm{He}$ explains this inequality behavior by a decrease in governmental intervention and the increase of more liberal economic policies.
} 
decreasing linear trends and the expenditure basic series has a significant U-pattern. When the estimated regression curves are plotted ${ }^{38}$ (Figure 6), we observe that the series for the developing countries are mainly decreasing in the period. The two series with a significant quadratic trend have their turning point late in the period: for the Gross extended series it is 1987 and for the Expenditure basic series, 1991. This generates a trend that is decreasing trough the period and increases slightly at the end.

Therefore, we can conclude that the OECD countries present a clear U-pattern time trend, with a turning point around the late 1970s. In addition, for developing countries inequality has been mainly decreasing in the period, with a slight increase in the 1990s. Subsequently, although intercountry inequality is more variable, within-country trends are also significant.

\section{Figure 6: Estimated random-effects regression curves}

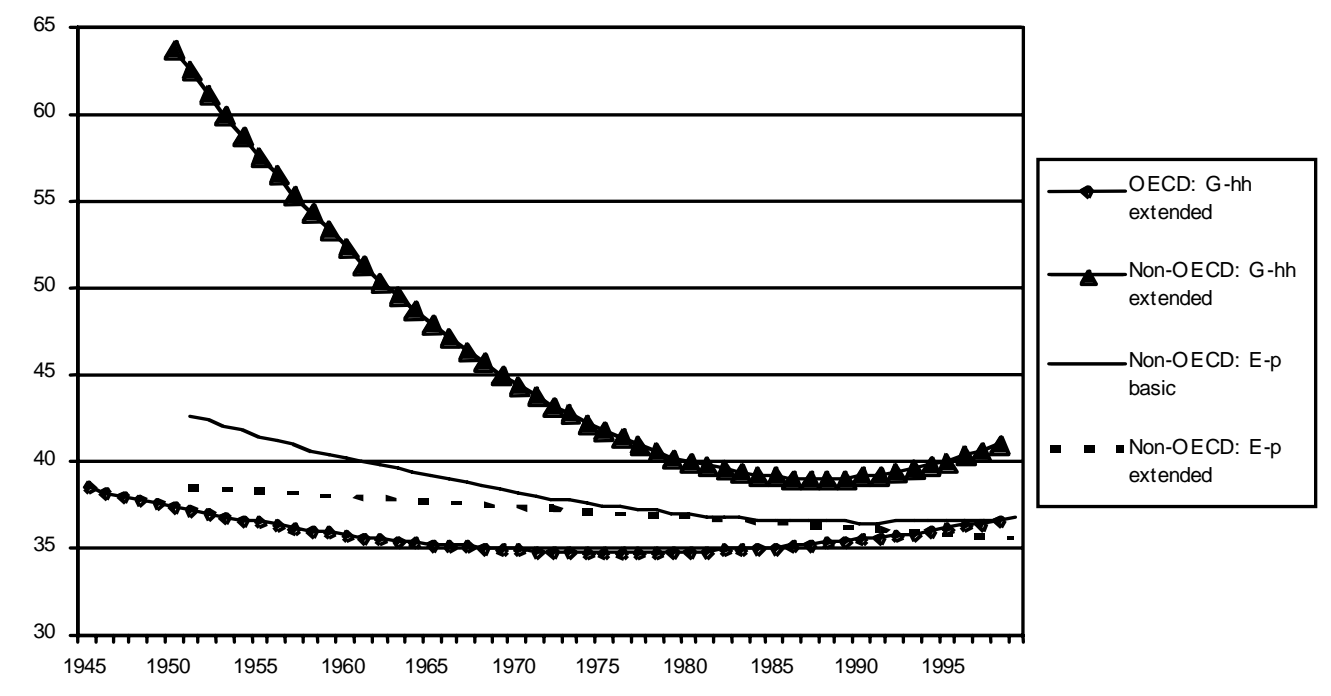

\subsection{Country-specific inter-temporal patterns}

Inequality changes over time have important policy implications. For instance, if inequality is stable over time, then economic growth has a direct impact on poverty reduction. Moreover, the particular level of inequality determines how much poor households benefit from countrywide growth. Conversely, significant shifts in inequality can offset the impact of growth on poor households, signal important socioeconomic changes and strengthen the importance of redistributive policies.

38 We only plot the OECD gross-household extended series, since the other series are very similar. The linear trend of the developing countries expenditure-person extended series is very similar to that of the basic series and thus, it is not plotted either. 
We focus now on country specific inequality trends. Again we use a linear and a quadratic time trend to test for inter-temporal variations in inequality, but now we use fixed-effects estimations to capture the individual coefficients for each country. Moreover, as some countries have more series with different reference units (i.e. household equivalent) we incorporate these series into the pooling to obtain more country observations. ${ }^{39}$

In the Appendix (Tables A-7 and A-8) we present the fixed-effects regressions for the basic and extended gross-household series. For the basic series $24 \%$ had a significant linear trend, 24\% a quadratic trend and $13 \%$ both. In total, $61 \%$ of the countries had some kind of time trend. For the extended series the figures increase to $32 \%, 29 \%$ and $26 \%$, leaving the total to $87 \%$. The differences between both series can be accounted by the increase in the individual country observations provided by the extended series.

Using panel data provides more observations per country and thus, a better approximation of the inequality trend. For each country we perform pooled regressions using all its basic series and then asses if there is any significant trend at a 5\% confidence level. Together with the results of the basic gross-household series, the results of the panel data estimations for all the series are presented in the Appendix (Table A-9). In some cases the panel data regressions confirm the results of the gross-household series, in others they provide other trends or produce a trend that was not present before. It is important to highlight that $71 \%$ of the countries for which we regressed the pooled data have some kind of significant time trend.

The different results can be a consequence of several factors: the number of series in each country, the increased number of observations provided by the panel data analysis and the difference in definitions (income concept and/or recipient unit). Basically, given the data we are working with, there are many ways to analyze any individual country. The presence of series with different definitions, the basic series and the extended series and the Atkinson indexes provide a richer source of information from where to draw inequality conclusions. What seems to be evident is that many countries present inequality time series with some significant trends and thus, withincountry inequality variations are indeed important.

\footnotetext{
${ }^{39}$ Note that we are not mixing different reference units in a same series, but using distinctive series, each with a different reference unit.
} 


\subsection{Poverty results}

We estimate poverty ratios for the three basic extended series. ${ }^{40}$ In general, poverty has been declining in most of the countries and as expected, there is no absolute poverty in OECD countries. In many Asian and Latin American countries the ratios have been declining (i.e. China and India) and have become zero for some (e.g. Indonesia and Thailand). The exception is the African continent, were the ratios continue to remain high. These results are consistent with Sala-i-Martin (2002a, b), who used a similar estimation technique. In Figure 7 we show the poverty ratios for the $\$ 2 /$ day poverty line for China, Mexico and Thailand.

These poverty results may seem surprising, especially the lack of poverty in some Southeast Asian countries. However, one must keep in mind that the poverty lines are analytical constructs that show minimum living standards in poor countries and do not reflect any relative poverty. For some countries there may be poverty as defined by national standards, though it disappears when an international absolute poverty line is used. Furthermore, the interrelation between growth and inequality is crucial to understand poverty reduction. To clarify this point, we have done some poverty numerics that show the relationship between income shares, GDP per capita and poverty ratios.

${ }^{40}$ Since some of the observations in these series have been adjusted for comparability reasons, we have some share data that does not correspond with the associated Gini values. Thus, we have some observations that present a lower or higher inequality than the non-adjusted data. There is no easy way to correct for this problem. However, since most of the adjustments were performed in OECD countries, the poverty results are mainly not affected, since there is no absolute poverty in these countries. The three exemptions are the gross-household series for Brazil, Chile and Mexico. For Brazil we did not use the adjusted data. Chile has higher poverty and Mexico lower poverty for the adjusted data than expected otherwise. 
Figure 7: \$2/day poverty ratios for selected countries

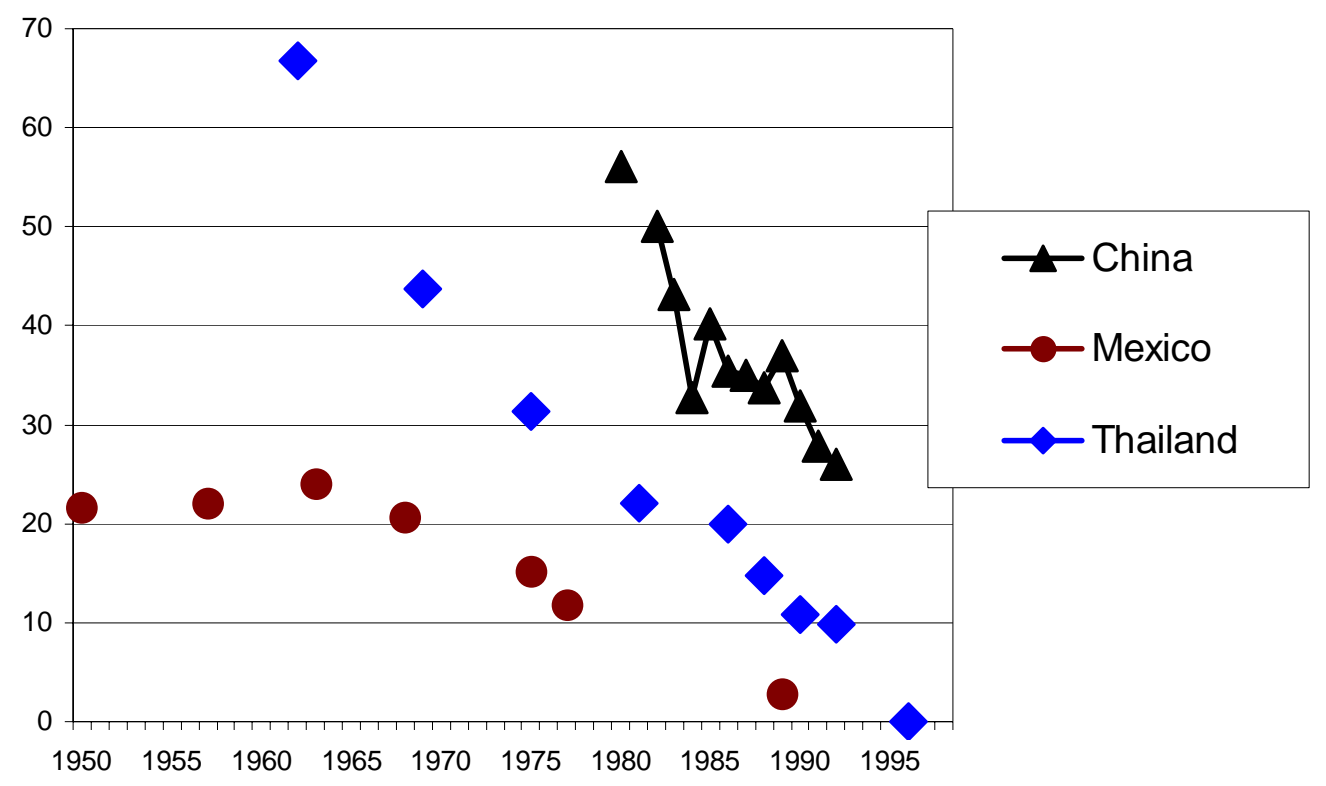

Using equation (15), for any given income share, we can establish the minimum GDP per capita needed to cross the poverty line. The income shares are determined by the underlying income distribution of each data point. For illustration purposes we obtain the average income shares for the three extended series and estimate the minimum GDP per capita that assures that the poverty line is crossed. ${ }^{41}$ Figure 8 shows that the required GDP per capita is higher for the gross-household series.

${ }^{41}$ We are implicitly assuming that growth does not change income inequality, although this is a controversial point (Dollar and Kraay, 2002). 
Figure 8: Minimum GDP per capita to cross $\$ 2 /$ day poverty line at different poverty ratios

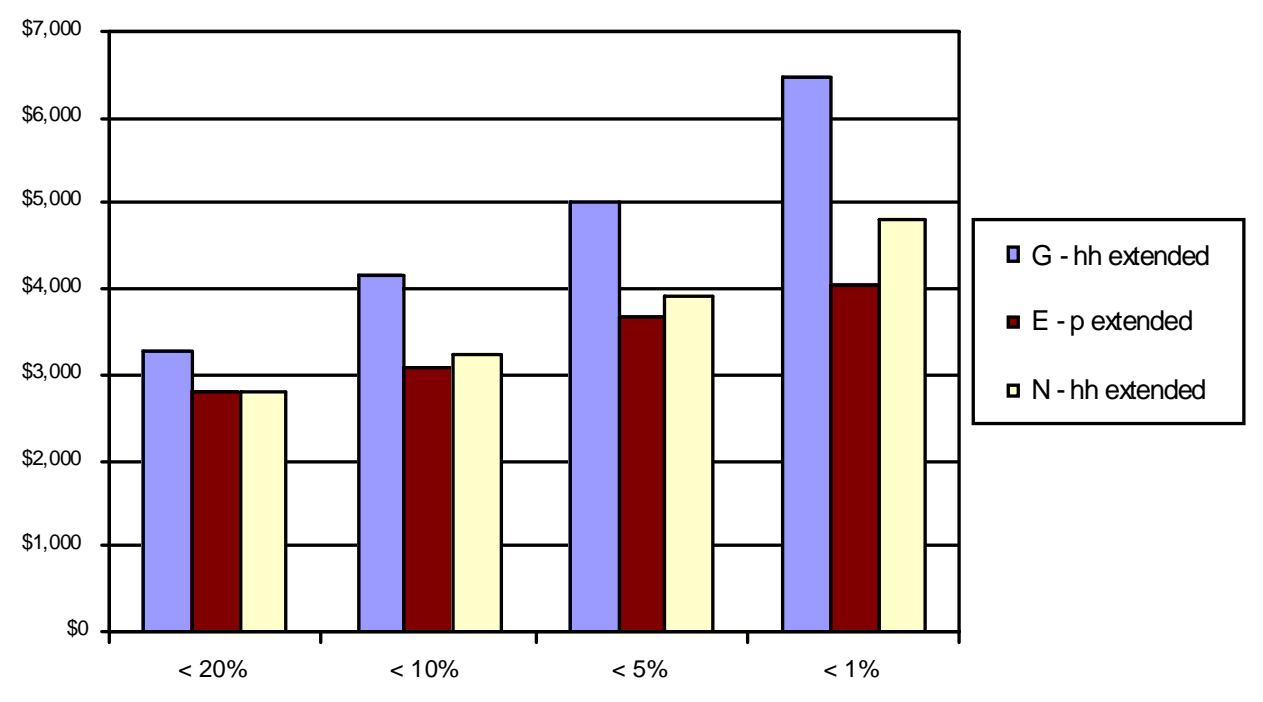

This is consistent with the fact that the series has higher inequality than the net and expenditure series. Moreover, the figure shows the percentage of the population that lives below the poverty line of $\$ 2 /$ day. For example, with a GDP per capita of at least $\$ 3000$, the poverty ratio is below $20 \%$ when inequality is measured by expenditure or net income. Equivalently, with a GDP per capita of at least $\$ 5000$ there is less than $1 \%$ of absolute poverty. However, these minimum total income requirements can vary when the country has extreme income distributions. Additionally, for a poverty line of $\$ 1 /$ day, the minimum GDP per capita is exactly half of the values shown in the figure.

Finally, we present the specific case of Thailand. In Figure 9 we plot the poverty ratio for $\$ 2 /$ day, the GDP per capita levels and the Gini coefficient for the gross-household series. The Gini coefficient has been relatively stable over the period, with an increase in the late 1980s and beginning of the 1990s. Nevertheless, there have been high rates of GDP per capita growth in the same period and this has allowed a sharp decrease in the poverty ratio. For 1996 the poverty ratio is zero, when the GDP per capita was above $\$ 7000$. The data is consistent with our poverty numerics: with a GDP of around $\$ 3000$ the poverty ratio was above 20\% and in 1996 the poverty ratio is zero, when the GDP per capita was above $\$ 6000$. 
Figure 9: Thailand: poverty ratios, Gini coefficients and GDP per capita

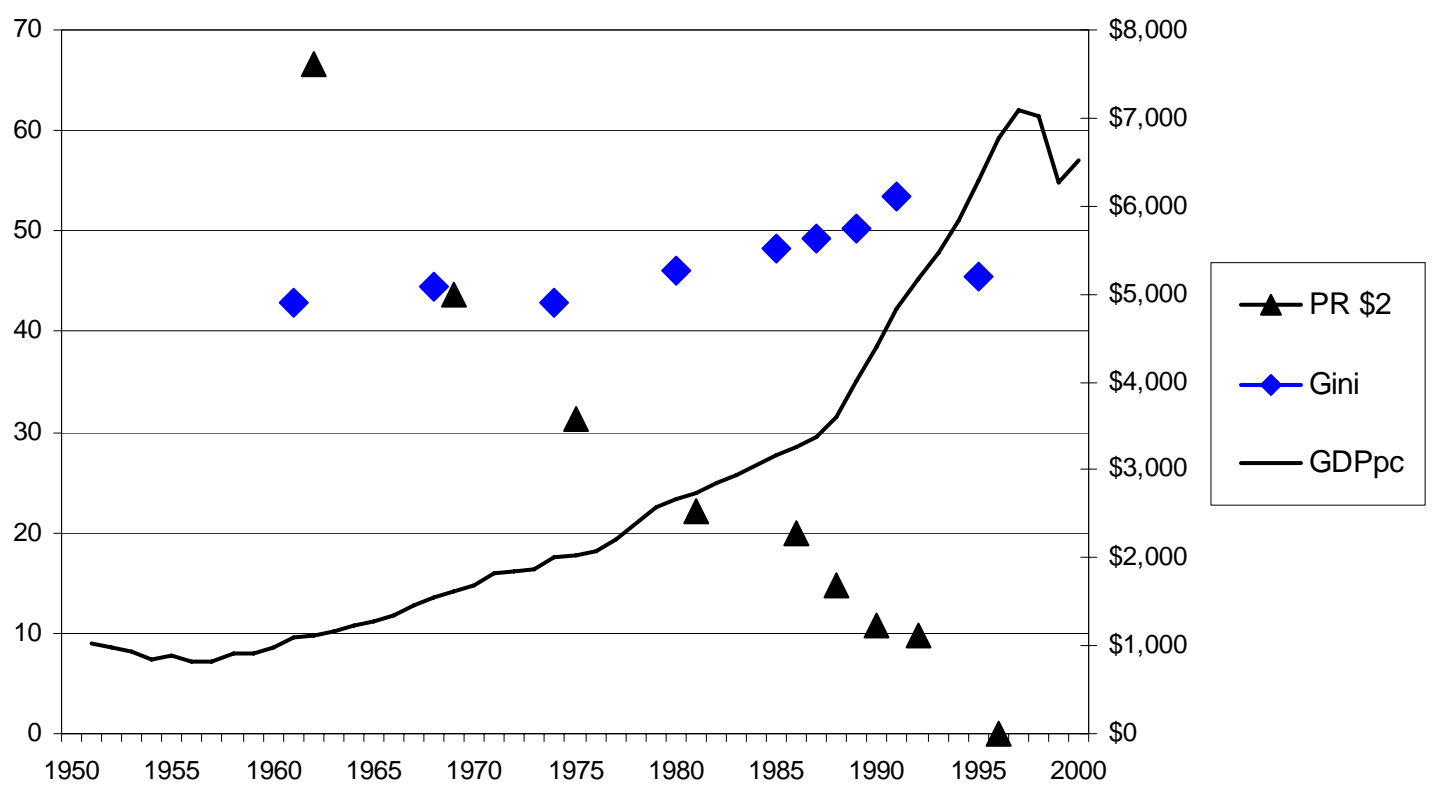

\section{Conclusions}

The empirical study of cross-country inequality benefits from, but is also limited by, the heterogeneity and vast amount of available data. Some of these limitations can be overcome by filtering the data with quality criteria. A complementary step is to make comparability assumptions and group data with different definitions. However, we believe we have convincingly shown that it is not a good idea (or sound practice) to collapse the whole available information set of a particular country into a single income inequality time series. We have demonstrated that using different income concepts in a same series may seriously affect inequality levels and time trends. Likewise, mixing some recipient units may also alter significantly the series. There are already important measurement errors implicit in most of the inequality data and freely mixing different concepts and reference units only adds more noise to the data. Furthermore, using dummy variable adjustments does not always correct for this problem and in some cases, increases the data distortions. Thus, the single time series approach followed in the recent literature should not be continued, and the recent body of literature based on those data should be reassessed.

As an alternative, we propose the use of more than one series per country, where each series is characterized by a different income concept and/or reference unit. Although an individual country 
may have several series, there are three series for which there is considerable world-wide coverage: gross-household, net-household and expenditure-person. Moreover, we have generated two main set of series, based on the reliability of the comparability assumptions followed. The "basic" series uses only strong comparability assumptions, while the "extended" series allows for less reliable assumptions, but has longer time series. In sum, this approach yields six main inequality series that can readily be used in empirical tests and within these series the implicit measurement error has been reduced.

We have also introduced improvements to existing methods for estimating Lorenz curves from grouped data. The approach is more extensive than the often-used POVCAL software. The Gini estimations obtained from the income share data are highly satisfactory and statistically comparable to the coefficients reported by the primary sources. Furthermore, using the resulting estimated Lorenz curves one can estimate Atkinson indexes, which are a conveniently complement to the information provided by the Gini coefficient. We find that in roughly a third of the cases both indexes report different inequality trends and thus, the use of both indexes is advisable in order to obtain robust conclusions about income inequality.

Finally, we have used our broadly comparable dataset to examine international patterns of inequality and poverty. A first conclusion is that between-country inequality variation is more significant than within-country. This suggests that country specific characteristics have a bigger role in explaining inequality levels than time trends. However, we also find that within-country inequality is still important and there are significant time trends in our series. Therefore, we reject the "glacial change" hypothesis (Li, et al., 1998) that inequality does not vary significantly over time. For the specific case of OECD countries, we clearly detect a U-shape pattern that confirms the "U-turn" hypothesis of Atkinson (2003). For developing countries the cross-country pattern is less clear, but it suggests a decrease in inequality for most of the analyzed period, with a slight increase in the 1990s. Country-specific time trends are diverse and it is difficult to spot precise trends. The choice of income concept, basic or extended series and the use of pool data may produce different results. Nevertheless, this variety of choice emphasizes the richness of our inequality dataset, which is not limited by a single series and provides wider information from where to draw conclusions. With respect to poverty, we find a decline in the poverty ratios in most of the countries covered by our sample. The only (though admittedly quite significant) exception is the poverty experience in the African continent. 


\section{References}

Atkinson, A.B. (1970). "On the Measurement of Inequality," Journal of Economic Theory, 2: 244-63.

Atkinson, A.B. (1997). "Bringing Income Distribution in from the Cold", Economic Journal, 107: $297-$ 321.

Atkinson, A.B. (2003). "Income Inequality in OECD Countries: Data and Explanations." Revised version of the paper presented at the CESifo conference on "Globalization, Inequality and WellBeing" in Munich, November 8-9, 2002.

Atkinson, A.B. and F. Bourguignon (2000). "Income Distribution and Economics," in Handbook of Income Distribution, Vol. 1, edited by A.B. Atkinson and F. Bourguignon. Elsevier, Amsterdam.

Atkinson, A.B. and A. Brandolini (2001). "Promise and Pitfalls in the Use of 'Secondary' Data-Sets: Income Inequality in OECD Countries," Journal of Economic Literature, 39: 771-99.

Atkinson, A.B., L. Rainwater and T.M. Smeeding (1995). Income Distribution in OECD countries. Evidence from the Luxembourg Income Study. OECD, Paris.

Barro, R. (2000). "Inequality and Growth in a Panel of Countries," Journal of Economic Growth, 5(1): 532.

Burniaux, J., T. Dang, D. Fore, M. Förster, M. Mira D'Ercole and H. Oxley (1998). "Income Distribution and Poverty in Selected OECD Countries," OECD, Economics Department, Working Paper No. 189.

Chen, S., G. Datt and M. Ravallion (1998). "POVCAL: A Program for Calculating Poverty Measures from Grouped Data," Policy Research Department, World Bank.

Chen, S. and M. Ravallion (2001). "How Did the World's Poorest Fare in the 1990s?" Review of Income and Wealth, 47: 283-300.

Chen, S. and M. Ravallion (2004). "How Have the World's Poorest Fare Since the Early 1980s?" mimeo, World Bank.

Cowell, F.A. (1995). Measuring Inequality. 2nd Ed. Harvester Wheatsheaf, Hemel Hempstead

Cowell, F.A. (2000). "Measurement of Inequality," in Handbook of Income Distribution, Vol. 1, edited by A.B. Atkinson and F. Bourguignon. Elsevier, Amsterdam.

Dalton, H. (1920). "The Measurement of the Inequality of Incomes," Economic Journal, 30(9): 348-361.

Datt, G. (1998). "Computational Tools for Poverty Measurement and Analysis," Food Consumption and Nutrition Division, International Food Policy Research Institute, FCND Discussion Paper No. 50. 
Deininger, K. and L. Squire (1996). "A New Data Set Measuring Income Inequality," World Bank Economic Review, 10(3): 565-91

Deininger, K. and L. Squire (2002). "Revisiting Inequality: New Data, New Results," The Egyptian Center for Economic Studies, Distinguished Lecture Series No. 18.

Dollar, D. and A. Kraay (2002). "Growth Is Good for the Poor," Journal of Economic Growth, 7(3): 195-225.

Kakwani, N. (1980). "On a Class of Poverty Measures," Econometrica, 48(2): 437-46.

Kakwani, N. and N. Podder (1973). "On the Estimation of Lorenz Curves from Grouped Observations," International Economic Review, 14(2): 278-92.

Kakwani, N. and N. Podder (1976). "Efficient Estimation of the Lorenz Curve and Associated Inequality Measures from Grouped Observations," Econometrica, 44(1): 137-148.

Kolm, S. (1969). "The Optimal Production of Social Justice," in Public Economics, edited by J. Margolis and H. Guitton. Macmillan, New York.

Kuznets, S. (1955). "Economic Growth and Income Inequality," American Economic Review, 65: $1-28$.

Li, H., L. Squire and H. Zou (1998). "Explaining International and Intertemporal Variations in Income Inequality," Economic Journal, 108: 26-43.

Ortega, P., G. Martín, A. Fernández, M. Ladoux and A. García. (1991). "A New Functional Form for Estimating Lorenz Curves," Review of Income and Wealth, 37(4): 447-52.

Paukert, F. (1973). "Income Distribution at Different Levels of Development: A Survey of Evidence," International Labour Review, 108(2): 97-125.

Rasche, R.H., J. Gaffney, A.Y. Koo and N. Obst (1980). "Functional Forms for Estimating the Lorenz Curve," Econometrica, 48: 1061-62.

Ravallion, M. (2001). "Growth, Inequality and Poverty: Looking Beyond Averages," World Development, 29: 1803-15.

Ravallion, M. (2004). "Pessimistic on Poverty?" The Economist, April 10.

Ravallion, M. and S. Chen (1997). "What Can New Survey Data Tell Us about Recent Changes in Living Standards in Developing and Transitional Economies?" World Bank Economic Review, 11: 357-82.

Ravallion, M., G. Datt and D. van de Walle (1991). "Qualifying Absolute Poverty in the Developing World," Review of Income and Wealth, 37: 345-361. 
Sala-i-Martin, X. (2002a). "The Disturbing 'Rise' in Global Income Inequality," NBER, Working Paper 8904.

Sala-i-Martin, X. (2002b). "The World Distribution of Income (Estimated from Individual Country Distributions)," NBER, Working Paper 8933.

Sarabia, J.-M., E. Castillo and D.J. Slottje (1999). "An Ordered Family of Lorenz Curves," Journal of Econometrics, 91: 43-60.

Shorrocks, A. (1983). "Ranking Income Distributions," Economica, 50: 3-17.

UNU/WIDER-UNDP (2000). World Income Inequality Database, Version 1.0, 12 September 2000.

Villaseñor, J.A. and B.C. Arnold (1989). "Elliptical Lorenz Curves," Journal of Econometrics, 40(2): $327-$ 38. 


\section{APPENDIX}

Table A-1: Summary statistics, Gross-Household Basic series

\begin{tabular}{|c|c|c|c|c|c|c|c|}
\hline Country & Obs. & Mean & St. dev. & $\operatorname{Max}$ & Min & Max-Min & Coverage \\
\hline AUS & 12 & 37.88 & 3.75 & 44.11 & 31.82 & 12.29 & $68 \sim 96$ \\
\hline BEL & 3 & 28.22 & 3.13 & 31.81 & 26.11 & 5.71 & $85 \sim 92$ \\
\hline BGD & 10 & 35.20 & 2.77 & 38.50 & 29.00 & 9.50 & $63 \sim 86$ \\
\hline BGR & 29 & 23.18 & 3.67 & 34.41 & 17.83 & 16.58 & $63 \sim 96$ \\
\hline BHS & 11 & 44.34 & 4.71 & 53.61 & 38.74 & 14.88 & $70 \sim 93$ \\
\hline BRA & 17 & 57.85 & 2.68 & 65.05 & 53.46 & 11.59 & $60 \sim 87$ \\
\hline CAN & 18 & 33.60 & 1.09 & 35.04 & 31.39 & 3.66 & $65 \sim 91$ \\
\hline CHL & 18 & 55.01 & 3.55 & 59.63 & 46.40 & 13.23 & $68 \sim 96$ \\
\hline $\mathrm{CHN}$ & 4 & 35.20 & 13.83 & 55.80 & 26.60 & 29.20 & $53 \sim 75$ \\
\hline COL & 7 & 51.69 & 1.90 & 54.52 & 49.24 & 5.28 & $70 \sim 92$ \\
\hline CRI & 5 & 47.52 & 3.02 & 51.40 & 44.69 & 6.72 & $61 \sim 83$ \\
\hline DEW & 8 & 32.07 & 2.16 & 35.56 & 29.40 & 6.16 & $73 \sim 84$ \\
\hline DNK & 6 & 36.46 & 4.69 & 41.27 & 30.98 & 10.30 & $78 \sim 92$ \\
\hline ESP & 5 & 33.19 & 3.24 & 36.30 & 27.77 & 8.53 & $65 \sim 91$ \\
\hline FRA & 7 & 43.10 & 6.08 & 49.00 & 34.72 & 14.28 & $56 \sim 84$ \\
\hline GBR & 4 & 33.87 & 5.44 & 40.38 & 28.40 & 11.97 & $69 \sim 95$ \\
\hline $\mathrm{HKG}$ & 8 & 44.24 & 3.61 & 52.00 & 39.68 & 12.32 & $71 \sim 96$ \\
\hline IND & 4 & 41.17 & 5.51 & 47.75 & 34.34 & 13.41 & $56 \sim 75$ \\
\hline JPN & 23 & 36.38 & 1.90 & 41.49 & 33.27 & 8.22 & $62 \sim 90$ \\
\hline KOR & 9 & 35.94 & 2.14 & 39.85 & 33.98 & 5.87 & $65 \sim 88$ \\
\hline LKA & 8 & 42.70 & 4.96 & 47.95 & 35.65 & 12.30 & $53 \sim 87$ \\
\hline MEX & 11 & 52.29 & 6.42 & 62.28 & 42.90 & 19.38 & $50 \sim 96$ \\
\hline MYS & 6 & 50.63 & 1.87 & 52.83 & 48.30 & 4.53 & $67 \sim 84$ \\
\hline NLD & 10 & 31.16 & 1.61 & 33.37 & 28.40 & 4.97 & $77 \sim 97$ \\
\hline NOR & 10 & 31.80 & 3.20 & 37.50 & 27.22 & 10.29 & $62 \sim 96$ \\
\hline NZL & 13 & 34.12 & 3.19 & 40.11 & 29.23 & 10.88 & $73 \sim 97$ \\
\hline PAK & 10 & 34.54 & 1.96 & 38.65 & 32.38 & 6.27 & $63 \sim 88$ \\
\hline PER & 4 & 50.08 & 3.69 & 55.00 & 46.43 & 8.57 & $71 \sim 97$ \\
\hline PHL & 11 & 47.61 & 2.64 & 51.45 & 43.61 & 7.83 & $56 \sim 97$ \\
\hline POL & 5 & 30.96 & 0.90 & 32.20 & 30.07 & 2.13 & $86 \sim 92$ \\
\hline PRI & 3 & 50.30 & 1.50 & 51.98 & 49.12 & 2.86 & $69 \sim 89$ \\
\hline SGP & 7 & 40.76 & 1.88 & 43.23 & 37.88 & 5.35 & $73 \sim 93$ \\
\hline SWE & 5 & 31.76 & 3.03 & 36.96 & 29.02 & 7.93 & $67 \sim 92$ \\
\hline THA & 11 & 46.88 & 3.57 & 53.53 & 42.90 & 10.63 & $62 \sim 96$ \\
\hline T'TO & 4 & 46.04 & 4.22 & 51.64 & 41.49 & 10.15 & $58 \sim 81$ \\
\hline TUR & 3 & 50.81 & 6.12 & 56.26 & 44.20 & 12.06 & $68 \sim 87$ \\
\hline TWN & 31 & 31.15 & 1.71 & 34.60 & 28.82 & 5.78 & $64 \sim 97$ \\
\hline USA & 53 & 38.21 & 1.79 & 42.72 & 35.34 & 7.38 & $44 \sim 97$ \\
\hline Average & 10.87 & 40.21 & 3.50 & 45.52 & 35.81 & 9.71 & \\
\hline Overall & 413 & 38.94 & 9.39 & 65.05 & 17.83 & 47.22 & $44 \sim 97$ \\
\hline \multirow{2}{*}{\multicolumn{2}{|c|}{$\begin{array}{l}\text { Between Country variation } \\
\text { Within Country variation }\end{array}$}} & \multicolumn{3}{|c|}{$89 \%$} & Countries & 38 & \\
\hline & & \multicolumn{3}{|c|}{$11 \%$} & $O E C D$ & 14 & $37 \%$ \\
\hline
\end{tabular}


Table A-2: Summary statistics, Net-Household Basic series

\begin{tabular}{cccccccc}
\hline Country & Obs. & Mean & St.dev. & Max & Min & Max-Min & Coverage \\
\hline AUS & 8 & 37.23 & 6.01 & 44.00 & 31.04 & 12.96 & $68 \sim 96$ \\
BEL & 4 & 27.08 & 0.96 & 28.39 & 26.11 & 2.29 & $79 \sim 92$ \\
CAN & 12 & 30.03 & 1.97 & 34.30 & 26.60 & 7.70 & $71 \sim 94$ \\
DEW & 7 & 29.98 & 2.35 & 33.56 & 27.40 & 6.16 & $63 \sim 83$ \\
DNK & 3 & 30.79 & 1.01 & 31.48 & 29.63 & 1.85 & $76 \sim 92$ \\
FIN & 10 & 30.43 & 2.35 & 33.93 & 26.37 & 7.55 & $77 \sim 91$ \\
FRA & 3 & 30.42 & 2.23 & 31.85 & 27.85 & 4.00 & $79 \sim 84$ \\
G BR & 32 & 32.79 & 2.57 & 38.38 & 26.23 & 12.15 & $61 \sim 95$ \\
IRL & 3 & 38.70 & 1.28 & 39.86 & 37.32 & 2.54 & $73 \sim 87$ \\
ITA & 25 & 35.19 & 4.58 & 42.00 & 28.78 & 13.22 & $48 \sim 95$ \\
MEX & 13 & 50.94 & 5.95 & 58.06 & 40.90 & 17.16 & $50 \sim 96$ \\
NLD & 16 & 29.17 & 2.14 & 32.40 & 24.66 & 7.74 & $75 \sim 94$ \\
NOR & 15 & 28.39 & 2.75 & 34.50 & 24.22 & 10.29 & $62 \sim 96$ \\
POL & 16 & 26.97 & 4.40 & 34.19 & 18.85 & 15.34 & $76 \sim 97$ \\
POR & 4 & 37.09 & 2.51 & 40.36 & 34.25 & 6.11 & $73 \sim 91$ \\
ROM & 9 & 26.76 & 3.21 & 31.26 & 22.88 & 8.38 & $89 \sim 97$ \\
SVK & 11 & 20.96 & 3.91 & 30.60 & 17.73 & 12.87 & $58 \sim 97$ \\
SWE & 5 & 28.73 & 2.41 & 32.61 & 26.44 & 6.17 & $67 \sim 92$ \\
TWN & 30 & 30.11 & 1.66 & 33.60 & 27.82 & 5.78 & $64 \sim 97$ \\
USA & 53 & 34.22 & 1.78 & 38.72 & 31.34 & 7.38 & $44 \sim 97$ \\
\hline Average & 13.95 & 31.80 & 2.80 & 36.20 & 27.82 & 8.38 & $44 \sim 97$ \\
Overall & 279 & 32.17 & 6.25 & 58.06 & 17.73 & 40.33 & \\
\hline \hline
\end{tabular}


Table A-3: Summary statistics, Expenditure-Person Basic series

\begin{tabular}{|c|c|c|c|c|c|c|c|}
\hline Country & Obs. & Mean & St. dev. & $\operatorname{Max}$ & Min & Max-Min & Coverage \\
\hline BGD & 3 & 30.22 & 2.98 & 33.64 & 28.23 & 5.41 & $89 \sim 96$ \\
\hline CIV & 5 & 38.67 & 1.97 & 41.20 & 36.64 & 4.56 & $85 \sim 95$ \\
\hline ESP & 3 & 33.41 & 1.37 & 34.90 & 32.18 & 2.71 & $74 \sim 91$ \\
\hline $\mathrm{EST}$ & 5 & 36.72 & 1.82 & 39.47 & 34.57 & 4.90 & $92 \sim 98$ \\
\hline GHA & 5 & 34.64 & 1.63 & 36.73 & 32.73 & 4.00 & $88 \sim 97$ \\
\hline GIN & 3 & 42.54 & 3.73 & 46.84 & 40.36 & 6.48 & $91 \sim 95$ \\
\hline HUN & 3 & 21.86 & 4.41 & 26.96 & 19.24 & 7.71 & $93 \sim 97$ \\
\hline IDN & 13 & 34.37 & 1.72 & 37.71 & 31.68 & 6.03 & $64 \sim 96$ \\
\hline IND & 33 & 32.56 & 2.17 & 37.48 & 29.10 & 8.38 & $51 \sim 97$ \\
\hline IRN & 5 & 43.23 & 1.41 & 45.45 & 41.88 & 3.57 & $69 \sim 84$ \\
\hline JAM & 9 & 41.07 & 2.96 & 45.58 & 36.47 & 9.11 & $71 \sim 96$ \\
\hline JOR & 4 & 39.38 & 3.80 & 44.21 & 36.33 & 7.87 & $80 \sim 97$ \\
\hline LKA & 3 & 34.46 & 4.32 & 38.80 & 30.15 & 8.65 & $87 \sim 95$ \\
\hline MRC & 3 & 39.27 & 0.24 & 39.53 & 39.09 & 0.44 & $84 \sim 99$ \\
\hline NGA & 5 & 43.71 & 5.07 & 50.60 & 36.93 & 13.67 & $86 \sim 97$ \\
\hline PER & 3 & 43.70 & 1.22 & 45.11 & 43.00 & 2.11 & $86 \sim 94$ \\
\hline POL & 3 & 30.10 & 2.75 & 32.66 & 27.20 & 5.47 & $92 \sim 96$ \\
\hline PHL & 4 & 42.66 & 2.46 & 46.06 & 40.68 & 5.38 & $85 \sim 97$ \\
\hline THA & 3 & 30.10 & 2.75 & 32.66 & 27.20 & 5.47 & $89 \sim 98$ \\
\hline TUN & 3 & 43.77 & 2.45 & 46.20 & 41.31 & 4.90 & $65 \sim 90$ \\
\hline TZA & 5 & 42.61 & 1.45 & 44.00 & 40.15 & 3.85 & $69 \sim 93$ \\
\hline ZMB & 4 & 45.04 & 9.66 & 59.01 & 38.15 & 20.86 & $91 \sim 96$ \\
\hline Average & 5.77 & 37.46 & 2.83 & 41.13 & 34.69 & 6.43 & \\
\hline Overall & 127 & 36.97 & 6.00 & 59.01 & 19.24 & 39.77 & $51 \sim 99$ \\
\hline \multirow{2}{*}{\multicolumn{3}{|c|}{$\begin{array}{l}\text { Between Country variation } \\
\text { Within Country variation }\end{array}$}} & $79 \%$ & \multirow{2}{*}{\multicolumn{2}{|c|}{$\begin{array}{l}\text { Countries } \\
\text { OECD }\end{array}$}} & 22 & \\
\hline & & & $21 \%$ & & & 1 & $5 \%$ \\
\hline
\end{tabular}


Table A-4: Summary statistics, Gross-Household Extended series

\begin{tabular}{|c|c|c|c|c|c|c|c|}
\hline Country & Obs. & Mean & St.dev. & $\operatorname{Max}$ & Min & Max-Min & Coverage \\
\hline AUS & 15 & 39.14 & 4.22 & 44.22 & 31.82 & 12.40 & $68 \sim 98$ \\
\hline BEL & 3 & 28.22 & 3.13 & 31.81 & 26.11 & 5.71 & $85 \sim 92$ \\
\hline BGD & 10 & 35.20 & 2.77 & 38.50 & 29.00 & 9.50 & $63 \sim 86$ \\
\hline BGR & 29 & 23.18 & 3.67 & 34.41 & 17.83 & 16.58 & $63 \sim 96$ \\
\hline BHS & 11 & 44.34 & 4.71 & 53.61 & 38.74 & 14.88 & $70 \sim 93$ \\
\hline BRA & 21 & 58.02 & 2.46 & 65.05 & 53.46 & 11.59 & $60 \sim 96$ \\
\hline BRB & 3 & 47.76 & 0.79 & 48.27 & 46.85 & 1.42 & $51 \sim 79$ \\
\hline CAN & 18 & 33.60 & 1.09 & 35.04 & 31.39 & 3.66 & $65 \sim 91$ \\
\hline CHL & 18 & 55.01 & 3.55 & 59.63 & 46.40 & 13.23 & $68 \sim 96$ \\
\hline $\mathrm{CHN}$ & 16 & 32.42 & 7.12 & 55.80 & 24.36 & 31.44 & $53 \sim 92$ \\
\hline COL & 11 & 53.95 & 5.20 & 64.53 & 47.83 & 16.70 & $64 \sim 94$ \\
\hline CRI & 12 & 47.17 & 2.95 & 53.54 & 43.90 & 9.64 & $61 \sim 95$ \\
\hline DEW & 8 & 32.07 & 2.16 & 35.56 & 29.40 & 6.16 & $73 \sim 84$ \\
\hline DNK & 15 & 33.71 & 3.96 & 41.27 & 28.29 & 12.98 & $63 \sim 95$ \\
\hline DOM & 4 & 47.07 & 3.55 & 51.00 & 43.29 & 7.71 & $76 \sim 92$ \\
\hline ECU & 3 & 47.00 & 7.94 & 53.00 & 38.00 & 15.00 & $68 \sim 94$ \\
\hline ESP & 5 & 33.19 & 3.24 & 36.30 & 27.77 & 8.53 & $65 \sim 91$ \\
\hline EST & 6 & 31.97 & 7.23 & 37.75 & 21.00 & 16.75 & $88 \sim 96$ \\
\hline FIN & 3 & 35.61 & 10.17 & 47.35 & 29.47 & 17.88 & $62 \sim 98$ \\
\hline FRA & 7 & 42.98 & 6.97 & 52.09 & 34.72 & 17.36 & $56 \sim 84$ \\
\hline GBR & 15 & 30.22 & 3.63 & 40.38 & 27.20 & 13.18 & $64 \sim 95$ \\
\hline GTM & 4 & 56.10 & 5.18 & 59.56 & 48.40 & 11.16 & $79 \sim 89$ \\
\hline HKG & 9 & 44.74 & 3.69 & 52.00 & 39.68 & 12.32 & $65 \sim 96$ \\
\hline HND & 7 & 55.04 & 3.98 & 61.88 & 50.00 & 11.88 & $68 \sim 93$ \\
\hline IND & 5 & 39.54 & 6.01 & 47.75 & 33.00 & 14.75 & $56 \sim 75$ \\
\hline JPN & 23 & 36.38 & 1.90 & 41.49 & 33.27 & 8.22 & $62 \sim 90$ \\
\hline KOR & 9 & 35.94 & 2.14 & 39.85 & 33.98 & 5.87 & $65 \sim 88$ \\
\hline LKA & 8 & 42.70 & 4.96 & 47.95 & 35.65 & 12.30 & $53 \sim 87$ \\
\hline MEX & 11 & 52.29 & 6.42 & 62.28 & 42.90 & 19.38 & $50 \sim 96$ \\
\hline MYS & 7 & 50.33 & 1.89 & 52.83 & 48.30 & 4.53 & $67 \sim 89$ \\
\hline NGA & 3 & 40.77 & 8.87 & 51.00 & 35.18 & 15.82 & $59 \sim 82$ \\
\hline NLD & 11 & 32.41 & 4.41 & 44.89 & 28.40 & 16.49 & $62 \sim 91$ \\
\hline NOR & 11 & 32.25 & 3.37 & 37.50 & 27.22 & 10.29 & $63 \sim 91$ \\
\hline NZL & 13 & 34.12 & 3.19 & 40.11 & 29.23 & 10.88 & $73 \sim 97$ \\
\hline PAK & 11 & 34.77 & 2.00 & 38.65 & 32.38 & 6.27 & $63 \sim 88$ \\
\hline PAN & 7 & 54.54 & 4.50 & 58.92 & 47.46 & 11.46 & $70 \sim 97$ \\
\hline PER & 6 & 52.77 & 6.25 & 63.95 & 46.43 & 17.52 & $61 \sim 97$ \\
\hline PHL & 11 & 47.61 & 2.64 & 51.45 & 43.61 & 7.83 & $56 \sim 97$ \\
\hline POL & 5 & 30.96 & 0.90 & 32.20 & 30.07 & 2.13 & $86 \sim 92$ \\
\hline PRI & 4 & 49.15 & 2.61 & 51.98 & 45.68 & 6.30 & $63 \sim 89$ \\
\hline ROM & 4 & 28.52 & 1.94 & 31.20 & 27.10 & 4.10 & $89 \sim 94$ \\
\hline RUS & 7 & 32.16 & 6.58 & 40.01 & 25.90 & 14.11 & $88 \sim 98$ \\
\hline SUN/RUS & 10 & 30.27 & 6.21 & 40.01 & 24.52 & 15.49 & $80 \sim 98$ \\
\hline SGP & 7 & 40.76 & 1.88 & 43.23 & 37.88 & 5.35 & $73 \sim 93$ \\
\hline SLV & 4 & 51.10 & 2.29 & 53.00 & 48.40 & 4.60 & $65 \sim 95$ \\
\hline SUN & 4 & 26.00 & 1.24 & 27.54 & 24.52 & 3.02 & $80 \sim 89$ \\
\hline SVK & 5 & 22.60 & 1.28 & 24.50 & 21.50 & 3.00 & $89 \sim 93$ \\
\hline SWE & 6 & 33.14 & 4.34 & 40.06 & 29.02 & 11.04 & $63 \sim 92$ \\
\hline THA & 11 & 46.88 & 3.57 & 53.53 & 42.90 & 10.63 & $62 \sim 96$ \\
\hline TTO & 5 & 45.80 & 3.69 & 51.64 & 41.49 & 10.15 & $57 \sim 81$ \\
\hline TUR & 3 & 50.81 & 6.12 & 56.26 & 44.20 & 12.06 & $68 \sim 87$ \\
\hline TWN & 31 & 31.15 & 1.71 & 34.60 & 28.82 & 5.78 & $64 \sim 97$ \\
\hline UKR & 8 & 27.96 & 5.08 & 34.43 & 21.82 & 12.61 & $80 \sim 97$ \\
\hline USA & 53 & 38.21 & 1.79 & 42.72 & 35.34 & 7.38 & $44 \sim 97$ \\
\hline VEN & 12 & 43.88 & 3.26 & 49.63 & 37.68 & 11.95 & $62 \sim 97$ \\
\hline YUF & 9 & 33.40 & 1.82 & 37.68 & 31.84 & 5.84 & $63 \sim 90$ \\
\hline ZAF & 3 & 61.34 & 2.09 & 63.00 & 59.00 & 4.00 & $90 \sim 95$ \\
\hline Average & 10.09 & 40.34 & 3.86 & 46.02 & 35.25 & 10.77 & \\
\hline Overall & 580 & 38.97 & 9.96 & 65.05 & 17.83 & 47.22 & $44 \sim 98$ \\
\hline \multirow{2}{*}{\multicolumn{3}{|c|}{$\begin{array}{l}\text { Between Country variation } \\
\text { Within Country variation }\end{array}$}} & \multicolumn{2}{|l|}{$87 \%$} & Countries & 57 & \\
\hline & & & $13 \%$ & & $O E C D$ & 15 & $26 \%$ \\
\hline
\end{tabular}


Table A-5: Summary statistics, Net-Household Extended series

\begin{tabular}{cccccccc}
\hline Country & Obs. & Mean & St. dev. & Max & Min & Max-Min & Coverage \\
\hline AUS & 8 & 37.23 & 6.01 & 44.00 & 31.04 & 12.96 & $68 \sim 96$ \\
BEL & 4 & 27.08 & 0.96 & 28.39 & 26.11 & 2.29 & $79 \sim 92$ \\
BGR & 6 & 34.10 & 2.34 & 37.10 & 30.98 & 6.13 & $92 \sim 97$ \\
CAN & 12 & 30.03 & 1.97 & 34.30 & 26.60 & 7.70 & $71 \sim 94$ \\
CHN & 4 & 35.33 & 6.54 & 43.00 & 28.40 & 14.60 & $78 \sim 95$ \\
CSK & 10 & 21.73 & 2.46 & 26.99 & 18.49 & 8.51 & $58 \sim 88$ \\
CZE & 11 & 22.03 & 3.15 & 27.93 & 18.84 & 9.09 & $58 \sim 97$ \\
CSK/CZE & 19 & 21.89 & 2.85 & 27.93 & 18.49 & 9.45 & $58 \sim 97$ \\
DEW & 7 & 29.98 & 2.35 & 33.56 & 27.40 & 6.16 & $63 \sim 83$ \\
DNK & 6 & 32.07 & 1.59 & 33.79 & 29.63 & 4.16 & $76 \sim 95$ \\
EST & 7 & 37.94 & 2.31 & 41.02 & 33.80 & 7.21 & $92 \sim 98$ \\
FIN & 10 & 30.43 & 2.35 & 33.93 & 26.37 & 7.55 & $77 \sim 91$ \\
FRA & 3 & 30.42 & 2.23 & 31.85 & 27.85 & 4.00 & $79 \sim 84$ \\
GBR & 32 & 32.79 & 2.57 & 38.38 & 26.23 & 12.15 & $61 \sim 95$ \\
GRC & 3 & 35.89 & 4.82 & 41.30 & 32.06 & 9.24 & $74 \sim 88$ \\
HUN & 14 & 23.31 & 1.52 & 25.79 & 20.36 & 5.43 & $62 \sim 98$ \\
IRL & 3 & 38.70 & 1.28 & 39.86 & 37.32 & 2.54 & $73 \sim 87$ \\
ITA & 25 & 35.19 & 4.58 & 42.00 & 28.78 & 13.22 & $48 \sim 95$ \\
MEX & 13 & 50.94 & 5.95 & 58.06 & 40.90 & 17.16 & $50 \sim 96$ \\
NLD & 16 & 29.17 & 2.14 & 32.40 & 24.66 & 7.74 & $75 \sim 94$ \\
NOR & 15 & 28.39 & 2.75 & 34.50 & 24.22 & 10.29 & $62 \sim 96$ \\
POL & 16 & 26.97 & 4.40 & 34.19 & 18.85 & 15.34 & $76 \sim 97$ \\
POR & 4 & 37.09 & 2.51 & 40.36 & 34.25 & 6.11 & $73 \sim 91$ \\
ROM & 9 & 26.76 & 3.21 & 31.26 & 22.88 & 8.38 & $89 \sim 97$ \\
SVK & 11 & 20.96 & 3.91 & 30.60 & 17.73 & 12.87 & $58 \sim 97$ \\
CSK/SVK & 19 & 20.71 & 2.15 & 24.81 & 17.73 & 7.08 & $58 \sim 97$ \\
SWE & 12 & 29.41 & 1.92 & 32.70 & 26.44 & 6.26 & $67 \sim 96$ \\
TWN & 30 & 30.11 & 1.66 & 33.60 & 27.82 & 5.78 & $64 \sim 97$ \\
UKR & 8 & 27.46 & 5.08 & 33.93 & 21.32 & 12.61 & $80 \sim 97$ \\
USA & 53 & 34.22 & 1.78 & 38.72 & 31.34 & 7.38 & $44 \sim 97$ \\
YUG & 8 & 33.48 & 6.54 & 45.57 & 27.32 & 18.24 & $90 \sim 97$ \\
YUG/YUF & 9 & 32.21 & 7.22 & 45.57 & 22.00 & 23.57 & $78 \sim 97$ \\
\hline Average & 12.72 & 30.75 & 3.22 & 35.86 & 26.44 & 9.41 & \\
Overall & 407 & 30.41 & 6.94 & 58.06 & 17.73 & 40.33 & $44 \sim 98$ \\
\hline \hline & & & & & & & \\
\hline
\end{tabular}


Table A-6: Summary statistics, Expenditure-Person Extended series

\begin{tabular}{|c|c|c|c|c|c|c|c|}
\hline Country & Obs. & Mean & St. dev. & $\operatorname{Max}$ & Min & Max-Min & Coverage \\
\hline BGD & 6 & 33.46 & 4.37 & 39.19 & 28.23 & 10.96 & $73 \sim 96$ \\
\hline BGR & 6 & 25.10 & 2.34 & 28.10 & 21.98 & 6.13 & $92 \sim 97$ \\
\hline CAN & 6 & 22.10 & 1.15 & 23.60 & 20.70 & 2.90 & $78 \sim 92$ \\
\hline CIV & 5 & 38.67 & 1.97 & 41.20 & 36.64 & 4.56 & $85 \sim 95$ \\
\hline DEW & 3 & 23.25 & 0.41 & 23.68 & 22.88 & 0.80 & $73 \sim 83$ \\
\hline EGY & 5 & 36.18 & 5.52 & 42.00 & 28.94 & 13.06 & $59 \sim 95$ \\
\hline ESP & 10 & 25.34 & 1.41 & 26.98 & 22.59 & 4.39 & $74 \sim 96$ \\
\hline EST & 5 & 36.72 & 1.82 & 39.47 & 34.57 & 4.90 & $92 \sim 98$ \\
\hline GHA & 5 & 34.64 & 1.63 & 36.73 & 32.73 & 4.00 & $88 \sim 97$ \\
\hline GIN & 3 & 42.54 & 3.73 & 46.84 & 40.36 & 6.48 & $91 \sim 95$ \\
\hline GRC & 3 & 34.60 & 1.15 & 35.35 & 33.28 & 2.07 & $74 \sim 88$ \\
\hline HUN & 3 & 21.86 & 4.41 & 26.96 & 19.24 & 7.71 & $93 \sim 97$ \\
\hline IDN & 13 & 34.37 & 1.72 & 37.71 & 31.68 & 6.03 & $64 \sim 96$ \\
\hline IND & 33 & 32.56 & 2.17 & 37.48 & 29.10 & 8.38 & $51 \sim 97$ \\
\hline IRN & 5 & 43.23 & 1.41 & 45.45 & 41.88 & 3.57 & $69 \sim 84$ \\
\hline JAM & 9 & 41.07 & 2.96 & 45.58 & 36.47 & 9.11 & $71 \sim 96$ \\
\hline JOR & 4 & 39.38 & 3.80 & 44.21 & 36.33 & 7.87 & $80 \sim 97$ \\
\hline LKA & 6 & 32.34 & 3.92 & 38.80 & 27.38 & 11.42 & $63 \sim 95$ \\
\hline MRC & 3 & 39.27 & 0.24 & 39.53 & 39.09 & 0.44 & $84 \sim 99$ \\
\hline NGA & 5 & 43.71 & 5.07 & 50.60 & 36.93 & 13.67 & $86 \sim 97$ \\
\hline PAK & 10 & 31.46 & 0.82 & 32.43 & 29.89 & 2.55 & $69 \sim 96$ \\
\hline PER & 3 & 43.70 & 1.22 & 45.11 & 43.00 & 2.11 & $86 \sim 94$ \\
\hline PHL & 4 & 42.66 & 2.46 & 46.06 & 40.68 & 5.38 & $85 \sim 97$ \\
\hline POL & 4 & 28.82 & 3.41 & 32.66 & 24.96 & 7.70 & $86 \sim 96$ \\
\hline SGP & 4 & 37.55 & 2.99 & 40.95 & 33.70 & 7.25 & $78 \sim 93$ \\
\hline THA & 4 & 42.97 & 2.57 & 46.20 & 40.56 & 5.65 & $89 \sim 98$ \\
\hline TUN & 5 & 42.61 & 1.45 & 44.00 & 40.15 & 3.85 & $65 \sim 90$ \\
\hline TZA & 4 & 45.04 & 9.66 & 59.01 & 38.15 & 20.86 & $69 \sim 93$ \\
\hline UGA & 3 & 37.67 & 4.14 & 40.87 & 33.00 & 7.87 & $89 \sim 93$ \\
\hline $\mathrm{ZMB}$ & 3 & 46.54 & 3.06 & 49.75 & 43.65 & 6.10 & $91 \sim 96$ \\
\hline Average & 6.07 & 35.98 & 2.77 & 39.55 & 32.96 & 6.59 & \\
\hline Overall & 182 & 34.78 & 6.89 & 59.01 & 19.24 & 39.77 & $51 \sim 99$ \\
\hline ect conn & & & \multicolumn{2}{|c|}{$85 \%$} & ntries & 30 & \\
\hline bin Count & & & \multicolumn{2}{|c|}{$15 \%$} & $C D$ & 4 & $13 \%$ \\
\hline
\end{tabular}


Table A-7: Fixed-effects regressions on Gini Gross-Household Basic series

\begin{tabular}{|c|c|c|c|c|c|c|c|c|c|}
\hline & \multicolumn{3}{|c|}{ Linear trend } & \multicolumn{5}{|c|}{ Quadratic trend } & \\
\hline & $\alpha_{1}$ & $\alpha_{2}$ & p-value & $\beta_{1}$ & $\beta_{2}$ & $\mathrm{p}$-value & $\beta_{3}$ & $\mathrm{p}$-value & \\
\hline AUS & 23.97 & 0.356 & 0.000 & 21.89 & 0.470 & 0.518 & -0.001 & 0.874 & \\
\hline BEL & -9.80 & 0.839 & 0.120 & 302.82 & -12.933 & 0.548 & 0.151 & 0.522 & \\
\hline BGD & 30.44 & 0.152 & 0.180 & 56.32 & -1.598 & 0.118 & 0.028 & 0.086 & \\
\hline BGR & 16.56 & 0.180 & 0.002 & 33.69 & -0.817 & 0.042 & 0.014 & 0.013 & \\
\hline BHS & 58.22 & -0.347 & 0.001 & 34.06 & 0.946 & 0.462 & -0.017 & 0.314 & \\
\hline BRA & 57.75 & 0.003 & 0.976 & 53.40 & 0.283 & 0.580 & -0.004 & 0.580 & \\
\hline CAN & 31.45 & 0.060 & 0.474 & 41.29 & -0.533 & 0.465 & 0.009 & 0.414 & \\
\hline $\mathrm{CHL}$ & 43.58 & 0.269 & 0.002 & -6.58 & 2.928 & 0.000 & -0.034 & 0.000 & \\
\hline $\mathrm{CHN}$ & 65.73 & -1.357 & 0.000 & 95.00 & -4.761 & 0.000 & 0.083 & 0.000 & \\
\hline COL & 57.06 & -0.144 & 0.196 & 16.03 & 2.147 & 0.219 & -0.030 & 0.189 & \\
\hline CRI & 51.11 & -0.115 & 0.462 & 58.71 & -0.693 & 0.567 & 0.010 & 0.631 & \\
\hline DEW & 29.16 & 0.082 & 0.398 & 34.00 & -0.202 & 0.698 & 0.004 & 0.580 & \\
\hline DNK & 58.77 & -0.560 & 0.010 & 239.21 & -9.306 & 0.051 & 0.104 & 0.066 & \\
\hline ESP & 28.53 & 0.138 & 0.314 & -9.09 & 2.406 & 0.015 & -0.032 & 0.021 & \\
\hline FRA & 58.77 & -0.577 & 0.000 & 49.46 & 0.198 & 0.756 & -0.014 & 0.218 & \\
\hline GBR & 16.28 & 0.463 & 0.001 & 17.21 & 0.411 & 0.761 & 0.001 & 0.969 & \\
\hline HKG & 35.70 & 0.220 & 0.057 & 90.89 & -2.641 & 0.018 & 0.036 & 0.010 & \\
\hline IND & 33.01 & 0.363 & 0.066 & -6.17 & 4.195 & 0.001 & -0.085 & 0.001 & \\
\hline JPN & 38.45 & -0.066 & 0.355 & 39.37 & -0.126 & 0.791 & 0.001 & 0.899 & \\
\hline KOR & 34.70 & 0.038 & 0.740 & 5.96 & 1.878 & 0.079 & -0.028 & 0.084 & \\
\hline LKA & 43.96 & -0.043 & 0.644 & 63.58 & -1.731 & 0.000 & 0.031 & 0.000 & \\
\hline MEX & 61.03 & -0.258 & 0.000 & 51.09 & 0.575 & 0.015 & -0.013 & 0.000 & \\
\hline MYS & 51.30 & -0.021 & 0.914 & -5.49 & 3.587 & 0.082 & -0.056 & 0.080 & a/ \\
\hline NLD & 25.38 & 0.128 & 0.332 & 1.40 & 1.225 & 0.486 & -0.012 & 0.532 & \\
\hline NOR & 38.90 & -0.193 & 0.022 & 43.66 & -0.482 & 0.338 & 0.004 & 0.561 & \\
\hline NZL & 18.86 & 0.379 & 0.001 & 3.63 & 1.136 & 0.286 & -0.009 & 0.475 & \\
\hline PAK & 37.65 & -0.099 & 0.299 & 46.45 & -0.670 & 0.493 & 0.009 & 0.557 & \\
\hline PER & 61.09 & -0.243 & 0.065 & 124.15 & -3.663 & 0.062 & 0.043 & 0.081 & a/ \\
\hline PHL & 48.63 & -0.031 & 0.580 & 50.18 & -0.146 & 0.647 & 0.002 & 0.714 & \\
\hline POL & 28.64 & 0.050 & 0.932 & -365.52 & 17.268 & 0.488 & -0.188 & 0.489 & \\
\hline PRI & 54.22 & -0.109 & 0.564 & 75.98 & -1.383 & 0.497 & 0.018 & 0.530 & \\
\hline SGP & 37.59 & 0.078 & 0.616 & 44.82 & -0.292 & 0.874 & 0.005 & 0.840 & \\
\hline SWE & 39.99 & -0.220 & 0.106 & 74.55 & -2.234 & 0.052 & 0.028 & 0.078 & a/ \\
\hline THA & 39.67 & 0.196 & 0.009 & 33.23 & 0.587 & 0.286 & -0.005 & 0.474 & \\
\hline TTO & 48.93 & -0.101 & 0.516 & 12.34 & 3.103 & 0.004 & -0.062 & 0.003 & \\
\hline TUR & 71.20 & -0.618 & 0.001 & 89.36 & -1.715 & 0.559 & 0.016 & 0.708 & \\
\hline TWN & 30.19 & 0.025 & 0.635 & 49.33 & -1.037 & 0.007 & 0.014 & 0.006 & \\
\hline \multirow[t]{3}{*}{ USA } & 36.84 & 0.049 & 0.041 & 40.29 & -0.307 & 0.000 & 0.006 & 0.000 & \\
\hline & R-square & & 0.93 & & R-square & & 0.96 & & \\
\hline & F-statistic & & 128.4 & & F-statistic & & 87.5 & & \\
\hline
\end{tabular}

Note: a/ We reject the null hypothesis that both coefficients are zero at a 95\% confidence level. 
Table A-8: Fixed-effects regressions on Gini Gross-Household Extended series

\begin{tabular}{|c|c|c|c|c|c|c|c|c|c|c|c|}
\hline & \multicolumn{4}{|c|}{ Linear trend } & \multicolumn{7}{|c|}{ Quadratic trend } \\
\hline & $\alpha_{1}$ & $\alpha_{2}$ & $\mathrm{SE}$ & $\mathrm{p}$-value & $\beta_{1}$ & $\beta_{2}$ & $\mathrm{SE}$ & $\mathrm{p}$-value & $\beta_{3}$ & $\mathrm{SE}$ & p-value \\
\hline AUS & 23.30 & 0.381 & 0.084 & 0.000 & 22.72 & 0.411 & 0.576 & 0.477 & 0.000 & 0.007 & 0.959 \\
\hline BEL & -9.80 & 0.839 & 0.613 & 0.172 & 302.82 & -12.933 & 21.865 & 0.555 & 0.151 & 0.240 & 0.529 \\
\hline BGD & 30.44 & 0.152 & 0.129 & 0.239 & 56.32 & -1.598 & 1.037 & 0.124 & 0.028 & 0.016 & 0.091 \\
\hline BGR & 16.56 & 0.180 & 0.064 & 0.005 & 33.69 & -0.817 & 0.408 & 0.046 & 0.014 & 0.006 & 0.014 \\
\hline BHS & 58.22 & -0.347 & 0.115 & 0.003 & 34.06 & 0.946 & 1.308 & 0.470 & -0.017 & 0.017 & 0.322 \\
\hline BRA & 56.87 & 0.029 & 0.077 & 0.710 & 57.52 & -0.009 & 0.375 & 0.980 & 0.001 & 0.005 & 0.918 \\
\hline CAN & 31.45 & 0.060 & 0.096 & 0.530 & 41.29 & -0.533 & 0.741 & 0.472 & 0.009 & 0.011 & 0.422 \\
\hline $\mathrm{CHL}$ & 43.58 & 0.269 & 0.099 & 0.007 & -6.58 & 2.928 & 0.672 & 0.000 & -0.034 & 0.008 & 0.000 \\
\hline $\mathrm{CHN}$ & 42.93 & -0.275 & 0.073 & 0.000 & 82.95 & -3.378 & 0.312 & 0.000 & 0.050 & 0.005 & 0.000 \\
\hline $\mathrm{COL}$ & 56.07 & -0.056 & 0.087 & 0.517 & 122.65 & -3.918 & 0.757 & 0.000 & 0.052 & 0.010 & 0.000 \\
\hline CRI & 53.49 & -0.165 & 0.088 & 0.061 & 55.89 & -0.311 & 0.481 & 0.519 & 0.002 & 0.007 & 0.760 \\
\hline DEW & 29.16 & 0.082 & 0.110 & 0.458 & 34.00 & -0.202 & 0.529 & 0.703 & 0.004 & 0.007 & 0.587 \\
\hline DNK & 44.44 & -0.253 & 0.097 & 0.010 & 11.97 & 1.597 & 0.512 & 0.002 & -0.025 & 0.007 & 0.000 \\
\hline DOM & 32.21 & 0.352 & 0.251 & 0.162 & 94.29 & -2.766 & 3.530 & 0.434 & 0.038 & 0.043 & 0.377 \\
\hline ECU & 24.65 & 0.532 & 0.146 & 0.000 & 147.15 & -6.789 & 9.820 & 0.490 & 0.097 & 0.130 & 0.456 \\
\hline ESP & 28.53 & 0.138 & 0.156 & 0.377 & -9.09 & 2.406 & 1.003 & 0.017 & -0.032 & 0.014 & 0.023 \\
\hline EST & -64.50 & 1.942 & 0.442 & 0.000 & -478.19 & 18.907 & 15.869 & 0.234 & -0.173 & 0.162 & 0.286 \\
\hline FIN & 45.03 & -0.281 & 0.068 & 0.000 & 83.28 & -2.527 & 0.420 & 0.000 & 0.030 & 0.006 & 0.000 \\
\hline FRA & 60.48 & -0.621 & 0.126 & 0.000 & 49.34 & 0.307 & 0.646 & 0.635 & -0.017 & 0.012 & 0.147 \\
\hline GBR & 17.76 & 0.419 & 0.099 & 0.000 & 26.33 & -0.100 & 0.571 & 0.861 & 0.007 & 0.008 & 0.359 \\
\hline $\mathrm{HKG}$ & 42.31 & 0.066 & 0.109 & 0.545 & 86.00 & -2.399 & 0.669 & 0.000 & 0.033 & 0.009 & 0.000 \\
\hline HND & 71.37 & -0.384 & 0.143 & 0.008 & 87.04 & -1.326 & 2.404 & 0.582 & 0.013 & 0.033 & 0.695 \\
\hline IND & 29.03 & 0.505 & 0.195 & 0.010 & -10.87 & 4.523 & 1.158 & 0.000 & -0.091 & 0.026 & 0.001 \\
\hline JPN & 38.45 & -0.066 & 0.082 & 0.417 & 39.37 & -0.126 & 0.484 & 0.794 & 0.001 & 0.007 & 0.901 \\
\hline KOR & 34.70 & 0.038 & 0.129 & 0.770 & 5.96 & 1.878 & 1.083 & 0.084 & -0.028 & 0.016 & 0.089 \\
\hline LKA & 43.96 & -0.043 & 0.107 & 0.685 & 63.58 & -1.731 & 0.405 & 0.000 & 0.031 & 0.007 & 0.000 \\
\hline MEX & 61.03 & -0.258 & 0.061 & 0.000 & 51.09 & 0.575 & 0.239 & 0.016 & -0.013 & 0.004 & 0.000 \\
\hline MYS & 53.10 & -0.082 & 0.160 & 0.609 & 21.58 & 1.801 & 1.320 & 0.173 & -0.027 & 0.019 & 0.153 \\
\hline NGA & 61.83 & -0.679 & 0.166 & 0.000 & 106.89 & -4.661 & 8.039 & 0.562 & 0.073 & 0.147 & 0.621 \\
\hline NLD & 43.75 & -0.265 & 0.095 & 0.005 & 74.78 & -2.073 & 0.459 & 0.000 & 0.024 & 0.006 & 0.000 \\
\hline NOR & 39.76 & -0.213 & 0.085 & 0.013 & 45.20 & -0.557 & 0.466 & 0.233 & 0.005 & 0.007 & 0.456 \\
\hline NZL & 18.86 & 0.379 & 0.130 & 0.004 & 3.63 & 1.136 & 1.083 & 0.295 & -0.009 & 0.013 & 0.483 \\
\hline PAK & 38.24 & -0.114 & 0.102 & 0.264 & 48.40 & -0.785 & 0.915 & 0.392 & 0.010 & 0.014 & 0.462 \\
\hline PAN & 49.02 & 0.129 & 0.127 & 0.310 & 116.42 & -3.341 & 1.046 & 0.002 & 0.042 & 0.013 & 0.001 \\
\hline PER & 68.50 & -0.398 & 0.096 & 0.000 & 87.21 & -1.586 & 0.577 & 0.006 & 0.016 & 0.008 & 0.039 \\
\hline PHL & 48.63 & -0.031 & 0.063 & 0.627 & 50.18 & -0.146 & 0.325 & 0.653 & 0.002 & 0.005 & 0.719 \\
\hline POL & 28.64 & 0.050 & 0.661 & 0.940 & -365.52 & 17.268 & 25.311 & 0.496 & -0.188 & 0.276 & 0.497 \\
\hline PRI & 46.40 & 0.086 & 0.154 & 0.577 & 29.63 & 1.200 & 1.092 & 0.273 & -0.017 & 0.016 & 0.305 \\
\hline ROM & 52.21 & -0.488 & 0.844 & 0.563 & 1160.15 & -46.240 & 37.861 & 0.223 & 0.472 & 0.390 & 0.228 \\
\hline SGP & -0.31 & 0.612 & 0.174 & 0.001 & 100.66 & -3.791 & 2.321 & 0.103 & 0.047 & 0.025 & 0.058 \\
\hline SLV & 37.59 & 0.078 & 0.178 & 0.659 & 44.82 & -0.292 & 1.866 & 0.876 & 0.005 & 0.023 & 0.843 \\
\hline SVK & 14.44 & 0.170 & 0.962 & 0.860 & -889.92 & 37.884 & 60.082 & 0.529 & -0.393 & 0.626 & 0.531 \\
\hline SWE & 44.23 & -0.321 & 0.120 & 0.008 & 71.53 & -2.073 & 0.802 & 0.010 & 0.026 & 0.012 & 0.029 \\
\hline THA & 39.67 & 0.196 & 0.085 & 0.021 & 33.23 & 0.587 & 0.559 & 0.294 & -0.005 & 0.008 & 0.482 \\
\hline TTO & 46.70 & -0.035 & 0.142 & 0.804 & 14.78 & 2.940 & 0.985 & 0.003 & -0.059 & 0.019 & 0.003 \\
\hline TUR & 71.20 & -0.618 & 0.218 & 0.005 & 89.36 & -1.715 & 2.981 & 0.565 & 0.016 & 0.042 & 0.713 \\
\hline TWN & 30.19 & 0.025 & 0.059 & 0.677 & 49.33 & -1.037 & 0.391 & 0.008 & 0.014 & 0.005 & 0.007 \\
\hline UKR & 45.79 & -0.388 & 0.229 & 0.092 & 273.83 & -10.567 & 2.579 & 0.000 & 0.112 & 0.028 & 0.000 \\
\hline USA & 36.84 & 0.049 & 0.027 & 0.072 & 40.29 & -0.307 & 0.087 & 0.000 & 0.006 & 0.002 & 0.000 \\
\hline VEN & 38.15 & 0.147 & 0.090 & 0.103 & 59.10 & -1.046 & 0.466 & 0.025 & 0.016 & 0.006 & 0.010 \\
\hline \multirow[t]{3}{*}{ YUF } & 41.62 & -0.207 & 0.132 & 0.118 & 45.51 & -0.467 & 0.902 & 0.605 & 0.004 & 0.014 & 0.772 \\
\hline & $\mathrm{R}$-square & \multicolumn{3}{|c|}{0.92} & \multicolumn{4}{|c|}{$\mathrm{R}$-square } & \multicolumn{2}{|l|}{0.96} & \\
\hline & F-statistic & \multicolumn{3}{|c|}{106.8} & \multicolumn{4}{|c|}{ F-statistic } & 92.96 & & \\
\hline
\end{tabular}

Note: a/ We reject the null hypothesis that both coefficients are zerotat a 95\% confidence level. 
Table A-9: Time trends, Gross-Household Basic series and panel data of all definitions

\begin{tabular}{|c|c|c|c|c|c|c|c|c|c|c|c|}
\hline & \multicolumn{2}{|c|}{ Gross-Household } & \multicolumn{3}{|c|}{ Fixed-effects } & & \multicolumn{2}{|c|}{ Gross-Household } & \multicolumn{3}{|c|}{ Fixed-effects } \\
\hline & Linear & Quad. & Linear & Quad. & Series & & Linear & Quad. & Linear & Quad. & Series \\
\hline AUS & 0.36 & & 0.30 & & 5 & JPN & & & & $\mathrm{U}$ & 1 \\
\hline BEL & & & & & n.l. & KOR & & & & & 1 \\
\hline BGD & & & & & 3 & LKA & & $\mathrm{U}$ & & & 3 \\
\hline BGR & 0.18 & U & 0.21 & & 2 & MEX & -0.26 & $\operatorname{inv} U$ & -0.19 & & 3 \\
\hline BHS & -0.35 & & -0.30 & & 1 & MYS & & $\operatorname{inv} U$ & & $\operatorname{inv} U$ & 1 \\
\hline BRA & & & 0.11 & & 2 & NGA & n.a. & n.a. & 1.19 & & 1 \\
\hline CAN & & & & & 4 & NLD & & & 0.17 & & 4 \\
\hline CHL & 0.27 & $\operatorname{inv} U$ & 0.28 & $\operatorname{inv} U$ & 2 & NOR & -0.19 & & -0.22 & & 4 \\
\hline CHN & -1.36 & $\mathrm{U}$ & & $\mathrm{U}$ & 3 & NZL & 0.38 & & 0.37 & & 1 \\
\hline CIV & n.a. & n.a. & & & 1 & PAK & & & & & 2 \\
\hline COL & & & & & 2 & PAN & n.a. & n.a. & & & 1 \\
\hline CRI & & & -0.18 & & 2 & PER & & $\mathrm{U}$ & & $\mathrm{U}$ & 2 \\
\hline CSK & n.a. & n.a. & -0.19 & & 1 & PHL & & & & & 3 \\
\hline CZE & n.a. & n.a. & & $\mathrm{U}$ & 1 & POL & & & 0.40 & $\mathrm{U}$ & 3 \\
\hline DEW & & & & $\mathrm{U}$ & 7 & PRI & & & & & n.l. \\
\hline DNK & -0.56 & & & $\operatorname{inv} U$ & 6 & ROM & n.a. & n.a. & 1.86 & & 1 \\
\hline EGY & n.a. & n.a. & -0.42 & & 1 & RUS & n.a. & n.a. & & & 1 \\
\hline ESP & & $\operatorname{inv} U$ & -0.15 & & 4 & SGP & & & & & 2 \\
\hline EST & n.a. & n.a. & & & 3 & SVK & n.a. & n.a. & -0.24 & $\mathrm{U}$ & 1 \\
\hline FIN & n.a. & n.a. & -0.18 & U & 3 & SWE & & $\mathrm{U}$ & & $\mathrm{U}$ & 4 \\
\hline FRA & -0.58 & & -0.49 & $\mathrm{U}$ & 3 & THA & 0.20 & & 0.19 & & 3 \\
\hline GBR & 0.46 & & 0.23 & $\mathrm{U}$ & 4 & TUN & n.a. & n.a. & & & 1 \\
\hline GHA & n.a. & n.a. & -0.41 & & 1 & TTO & & $\operatorname{inv} U$ & & & n.l. \\
\hline HKG & & $\mathrm{U}$ & 0.40 & & 1 & TUR & -0.62 & & & & n.l. \\
\hline HND & n.a. & n.a. & & & 1 & TWN & & $\mathrm{U}$ & & $\mathrm{U}$ & 2 \\
\hline HUN & n.a. & n.a. & & $\mathrm{U}$ & 2 & UKR & n.a. & n.a. & & $\mathrm{U}$ & 2 \\
\hline IND & & $\operatorname{inv} U$ & -0.68 & & 2 & USA & 0.05 & $\mathrm{U}$ & 0.50 & $\mathrm{U}$ & 4 \\
\hline IRN & n.a. & n.a. & & & 1 & VEN & n.a. & n.a. & & & 1 \\
\hline ITA & n.a. & n.a. & -0.21 & & 2 & YUF & n.a. & n.a. & & & 1 \\
\hline JAM & n.a. & n.a. & & $\operatorname{inv} U$ & 1 & YUG & n.a. & n.a. & & & 1 \\
\hline
\end{tabular}

Notes: "n.l." stands for countries without a series with more than five observations.

"n.a." is for countries without a Gross-HH basic series.

"U " refers to significant negative and positive quadratic coefficients for $\beta 2$ and $\beta 3$ respectively.

"inv $U$ " is assigned when $\beta 2$ and $\beta 3$ are significant, while positive and negative respectively. 